\title{
The Effects of Interparental Aggression on Children's Adjustment: The Moderating Role of Cognitive Appraisal and Coping
}

\author{
Mary Jo Rogers \\ Loyola University Chicago
}

Follow this and additional works at: https://ecommons.luc.edu/luc_diss

Part of the Psychology Commons

\section{Recommended Citation}

Rogers, Mary Jo, "The Effects of Interparental Aggression on Children's Adjustment: The Moderating Role of Cognitive Appraisal and Coping" (1994). Dissertations. 3467.

https://ecommons.luc.edu/luc_diss/3467

This Dissertation is brought to you for free and open access by the Theses and Dissertations at Loyola eCommons. It has been accepted for inclusion in Dissertations by an authorized administrator of Loyola eCommons. For more information, please contact ecommons@luc.edu. (c) (i) $(9)$

This work is licensed under a Creative Commons Attribution-Noncommercial-No Derivative Works 3.0 License. Copyright @ 1994 Mary Jo Rogers 
LOYOLA UNIVERSITY CHICAGO

THE EFFECTS OF INTERPARENTAL AGGRESSION

ON CHILDREN'S ADJUSTMENT: THE MODERATING ROLE OF COGNITIVE APPRAISAL AND COPING

A DISSERTATION SUBMITTED TO

THE FACULTY OF THE GRADUATE SCHOOL

IN CANDIDACY FOR THE DEGREE OF

DOCTOR OF PHILOSOPHY

DEPARTMENT OF PSYCHOLOGY

BY

MARY JO ROGERS

CHICAGO, ILLINOIS

MAY 1994 


\section{ACKNOWLEDGEMENTS}

The author wishes to thank the parents, teachers, principals, and children for their cooperation and participation in this study. Dr. Grayson N. Holmbeck deserves special consideration and gratitude for his support and guidance throughout this project. Appreciation is also extended to members of the committee, Dr. Maryse Richards, Dr. Ana Estrada, and Dr. Paul Jose for their helpful comments.

Finally, the author recognizes the unfailing support of family and friends, whose encouragement and vision sustained this work. 
ACKNOWLEDGEMENTS . . . . . . . . . . . . . . . . iii

LIST OF ILLUSTRATIONS . . . . . . . . . . . . . . . . v

LIST OF TABLES . . . . . . . . . . . . . . . . . . . vi vi

Chapter

I. INTRODUCTION AND REVIEW OF RELATED LITERATURE . . . . . . . . . . . . . . . . . 1

Dimensions of the Conflict . . . . . . . 3

Dimensions of the Family .......... . 5

Explanatory Models of the Effects of

Interparental Aggression on Children's

Adjustment . . . . . . . . . . . . . . . . . 9

Age and Gender as Moderating Variables . . . 17

Conclusions and Hypotheses . . . . . . 19

II. METHOD . . . . . . . . . . . . . 25

Subjects . . . . . . . . . . . . . 25

Procedures . . . . . . . . . . . . . 28

Measures . . . . . . . . . . . . 28

Statistical Analysis. . . . . . . . . 35

III. RESULTS . . . . . . . . . . . . . 38

Sample Characteristics . . . . . . . 38

Correlation Analyses . . . . . . . . . . . . 41

Analyses of Child Data . . . . . . . . . . . 42

Subscale Exploratory Analyses . . . . . . 49

Analyses of Parent Data . . . . . . . . 51

IV. DISCUSSION . . . . . . . . . . . . 59

Appendix

A. PARENT PERMISSION FORM AND LETTER . . . . . . 72

B. CHILD QUESTIONNAIRE . . . . . . . . . . 75

C. PARENT QUESTIONNAIRE . . . . . . . . . . 93

D. CHILDREN'S BELIEFS AND COPING SUBSCALES . . 109

REFERENCES . . . . . . . . . . . . . . . . . . . 116

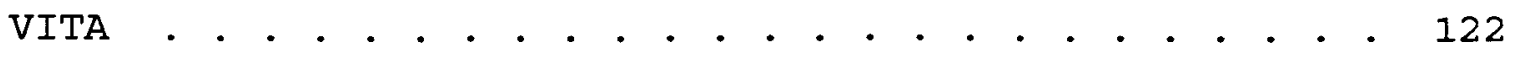




\section{LIST OF ILLUSTRATIONS}

Figure

Page

1. Model of the Direct and Moderating Effects of Cognitive Appraisal and Coping . . . . . . . . 24

2. Conflict by Avoidance Interaction Effects on Externalizing Behavior and Depression--Child Report . . 52

3. Conflict by Social Support Interaction Effect on Externalizing Behavior--Child Report . . . . . 53

4. Conflict by Peer Concerns Interaction Effect on Problem Behavior--Parent Report . . . . . . . 58 
Table

Page

1. Demographic Characteristics of Sample . . . . . 26

2. Means and Standard Deviations for Parent and Child Variables . . . . . . . . . . . . 39

3. Correlation Matrix for Parent-Report and Child-Report Variables with Alpha Coefficients . . . . . . . 43

4. Summary of Regression Analyses for Child-Reported Conflict and Dependent Variables-Cognitive Appraisal (Beliefs) . . . . . . . . . 46

5. Summary of Regression Analyses for Child-Reported Conflict and Dependent Variables--Coping . . . 48

6. Summary of Regression Analyses for Parent-Reported Conflict and Dependent Variables-Cognitive Appraisal (Beliefs) . . . . . . . . 55

7. Summary of Regression Analyses for Parent-Reported Conflict and Dependent Variables--Coping . . . 56 
CHAPTER I

INTRODUCTION AND REVIEW OF RELATED LITERATURE

Interparental aggression is of great concern due to its commonality and deleterious impact on the family. The results of national surveys indicate that about 12 percent of female respondents report incidents of spousal violence in the home (Straus \& Gelles, 1986; Straus, Gelles, \& Steinmetz, 1980). The damaging effects of couples' aggression have been found to extend beyond the marital dyad such that children who witness interparental aggression tend to have a higher incidence of maladjustment (Emery, 1982, 1988).

There has been a growing interest in studying the specific effects of witnessing verbal and physical interparental aggression on the psychological well-being of children. Research has begun to distinguish between the impact of witnessing parental conflict from the effects of being a victim of abuse (Hughes, 1988; Jouriles, Barling, \& O'Leary, 1987). Further, some researchers have attempted to separate the effects of witnessing parental conflict from the behavioral correlates of separation and divorce (Bishop \& Ingersol1, 1989; Long, 1986; Long, Forehand, Fauber, \& Brody, 1987). Other authors (see Grych \& Fincham, 1990 for 
a review) have highlighted the ways in which dimensions of the aggression, such as intensity and content, are associated with children's adjustment.

Previous research has provided a description of the various features associated with interparental aggression and child adjustment but fails to elucidate the processes linking the aggression and adjustment relationship. Consequently, researchers have begun to investigate the mechanisms by which such conflict influences child adjustment and psychopathology (Cummings, Pellegrini, Notarius, \& Cummings, 1989; Fauber, Forehand, Thomas, \& Wierson, 1990; Grych \& Fincham, 1990; Rosenberg, 1987). Grych and Fincham, for example, have presented a cognitive model for conceptualizing how children's understanding of interparental aggression plays a role in how such conflict impacts children's adjustment.

The purpose of the present research is to investigate the relationship between interparental aggression and children's adjustment through an analysis of the possible moderating role of children's cognitive processing and coping responses. Previous research focusing on the various dimensions of the conflict and of the family and the effects on child adjustment will be reviewed below. Subsequently, more recent models of the conflict-adjustment relationship will be presented with a discussion of the present 
hypotheses pertaining to the role of cognitive processing and coping.

Dimensions of the Conflict

Authors of previous research in this area have used a variety of measures and definitions of interparental aggression ranging from low levels of verbal disagreement to high levels of overt physical aggression. Across a variety of approaches, researchers have demonstrated a consistent relationship between interparental aggression and measures of maladjustment in children, such as aggressiveness, conduct disorders, and anxiety problems (Emery, 1982, 1988). Grych and Fincham (1990) point out, however, that it is important to consider the dimensions of the parental aggression when examining the relationship between witnessing parental aggression and child problems. Specifically Grych and Fincham found the following dimensions of aggression to be significant: frequency, intensity, content, and conflict resolution.

Frequency and Intensity. Research has shown that the frequency and intensity of interparental aggression are important variables in examining the relationship between observed aggression and child disturbance (Bishop \& Ingersoll, 1989; Jouriles, Murphy, \& O'Leary, 1989). Bishop and Ingersoll found that youth in families with high levels of verbal and physical interparental aggression had significantly more negative self-concept scores than youth 
in families with low levels of interparental hostility. Johnston, Gonzalez, and Campbell (1987) reported that the degree of verbal and physical aggression between divorcing parents was related to parental reports of child behavior problems, as found on the Somatic Complaint, WithdrawnUncommunicative, and Total Pathology scales of the Child Behavior Checklist (CBC; Achenbach \& Edelbrock, 1983). Jouriles et al. (1989) measured parental physical conflict while controlling for general marital discord. These authors found that interparental aggression contributed unique variance to the prediction of child problems, such as conduct disorder and inadequacyimmaturity, at clinical levels of disturbance. Moreover, children in maritally aggressive families exhibited problems at clinical levels more frequently than children in discordant, but nonaggressive families. Thus, research suggests that severe child problems are more typically associated with more frequent, intense (physical) marital conflict. In summarizing research on the intensity of conflict, Grych and Fincham concluded that conflict involving physical aggression is likely to be more upsetting to children and may be more closely linked to behavior problems than less intense forms of conflict.

Conflict Content and Resolution. Little research has examined the effects of conflict content and resolution on children exposed to interparental aggression. In reviewing 
available literature, Grych and Fincham (1990) state that children are sensitive to the content of their parents' conflicts and when the conflict concerns the child, (e.g., pertains to child management issues), the disturbance may be more distressing to the child. It was also concluded that the manner in which conflicts are resolved may affect the impact on children. Specifically, Cummings, Vogel, Cummings, and El-Sheikh (1989) found that six- to nine-year old children reported more negative affect when angry interactions between adults were left unresolved than when there were clear resolutions of conflict. Grych and Fincham (1990) suggest that inadequate conflict resolution may result in continued tension in the family, which may lead to more frequent episodes of conflict.

In summary, more frequent and more intense interparental conflict is associated with higher levels of child behavior problems. Preliminary findings suggest that conflict that pertains to the child may be more distressing to the child. When conflicts are resolved poorly and are followed by continued tension, the adverse effects on children's adjustment may be heightened.

Dimensions of the Family

Parent-Child Aggression. Previous research has considered a variety of familial variables when examining the effects of marital conflict. For instance, a number of authors have found that interspousal physical aggression is 
highly associated with parent-child aggression (Prescott \& Letko, 1977; Straus et al., 1980; Roy, 1977), which in turn is related to behavior problems in children (Hughes, 1988; Jouriles et al., 1987) and adolescents (Galambos \& Dixon, 1984). Thus, children who grow up in families in which their parents are physically abusive to one another are at higher risk of being battered themselves (Varma, 1977). However, it has been suggested that there is an effect of interparental conflict on child adjustment even when parent-child aggression is absent. Hughes (1988) found that nonabused children whose parents were physically abusive to one another scored significantly higher than comparison children on measures of anxiety, and scored lower on indices of self-esteem. On tests of child adjustment and psychopathology, the nonabused children in violent homes scored in the intermediate range between the abused children and the comparison group.

In contrast, Jouriles et al. (1987) found that parentchild (verbal and physical) aggression was more strongly linked to child behavior problems than parent reports of interspousal (verbal and physical) conflict. Level and type of conflict was measured using the Conflict Tactics Scale (CTS; Straus, 1979), which consists of both verbal and physical aggression items scored along a seven-point scale indicating frequency of occurrence.

These authors failed to find a significant relationship 
between interspousal aggression and child problems when parent-child aggression was partialled out. However, $91 \%$ of their sample reported that their homes were characterized by some degree of parent-child aggression in addition to the interparental aggression. Thus, their research may not have been a very powerful analysis of the possible effects of witnessing interspousal conflict because the sample of children exposed to interparental aggression, but not parent-child aggression, was inadequate. Jouriles et al. (1987) point out that the fact that their sample was derived from a victims' information bureau may have accounted for the substantial overlap between interparental and parentchild aggression, which was higher than reported in previous reviews (Straus et al., 1980). Previous studies on familial violence reveal that more research is needed to understand more fully the relationship between interparental aggression and the effects on nonabused children who witness such interactions.

Separation and Divorce. Research has also begun to look more specifically at the effects of interparental aggression as distinguished from the effects of marital status on children's well-being (Bishop \& Ingersoll, 1989; Long, 1986, 1987; Long, et al., 1987). Bishop and Ingersoll, for example, studied the effects of interparental aggression and family structure on children between the ages of eight and twelve. They found that youth in families 
characterized by marital hostility had significantly more negative self-concept scores, whereas no significant effect was found for family structure (intact, separated, or divorced) .

Similar significant effects of interparental aggression and nonsignificant effects of status were found for selfesteem of college females (Long, 1986), and for independently observed competence levels of young adolescents (Long et al., 1987). These findings indicate that observing interparental aggression can have an impact on child adjustment, apart from potential deleterious effects of parental divorce. Moreover, level of aggressiveness appears to be the critical variable across a variety of studies that have found significant effects of aggression on children's adjustment but nonsignificant effects of marital status.

In summary, previous research has demonstrated consistently that interparental aggression is associated with children's adjustment. Further, such research has illustrated various dimensions of the family and of the conflict itself that are linked to adjustment. These findings, however, do not explain the processes by which interparental aggression impacts child adjustment. More recently, researchers have presented models that attempt to elucidate the specific ways in which observing interparental 
aggression affects children and their psychological wellbeing .

Explanatory Models of The Effects of Interparental Aggression on Child Adjustment

Researchers studying the role of hypothesized mechanisms by which interparental aggression influences children's adjustment have suggested that this relationship is a function of social learning (Rosenberg, 1987), emotional sensitization (Cummings et al., 1989; Gottman \& Katz, 1989), and disrupted parenting (Fauber et al., 1990). Grych and Fincham (1990) have also proposed that children's cognitive appraisal plays an important role in children's adjustment problems. The literature addressing each of these models is summarized below.

The Role of Social Learning. Rosenberg (1987) states that witnessing parental aggression affects the child's cognitive and behavioral abilities to solve interpersonal problems by way of social learning. In partial support for this model, Rosenberg found that children who witnessed physical conflict performed less well on measures of interpersonal sensitivity, understanding social situations, and perspective-taking. These children also tended to choose ineffective (passive or aggressive) strategies to resolve interpersonal conflict with peers.

The Role of Emotional Sensitization. An alternative explanation for the effects of marital conflict on child 
behavior was proposed by Cummings et al. (1989) who observed children's responses to angry behavior performed by adult actors. These authors found that children whose parents engaged in physical aggressiveness showed: (a) increased preoccupation and concern regarding the angry adult interaction, (b) increased support-seeking directed to the adults, and (c) increased social responsibility or comforting the adults, when compared to control children. The authors suggested that children's history of exposure to conflict between parents influences their emotional reactions and coping strategies by way of emotional sensitization. These findings also support the notion that repeated exposure to hostility sensitizes children to discord such that they are more physiologically aroused and hypervigilant with regard to negative interpersonal cues.

In accord with Cummings et al. (1989), Gottman and Katz (1989) suggest that one of the processes that mediates child behavior problems is the child's ability to regulate emotional states, which may have a physiological basis. These authors utilized a variety of behavioral and physiological measures for assessing the functioning of children from homes characterized by severe interparental discord. They concluded that not all of the effects of interparental discord on children are mediated by parentchild interactions, but that there may be direct effects as well. Gottman and Katz found that children from parentally 
discordant homes play less well with peers (i.e., such children are less involved when interacting with peers or have more negative peer interactions). The authors suggested that the child may become sensitized to negative emotion and have difficulty regulating emotion, which subsequently influences the child's ability to interact with. peers. The authors point out that one of the best predictors of behavior problems is children's social relationships with peers and that peer difficulties are a leading indicator of psychiatric risk (Parker \& Asher, 1987). Gottman and Katz state that peer relationships may be influenced by the child's emotion regulation ability, which can be affected by the level of interparental aggression in the home.

The Role of Parenting. There is also support for the suggestion that disrupted parenting as it relates to interparental aggression affects children's adjustment. Fauber et al. (1990) studied the relationships among interparental aggression, detrimental parenting, and child problems. The authors found that there were negative effects of interparental conflict on child problems, which were mediated by rejection and withdrawal in the parentchild relationship. The authors added, however, that there may be other variables, such as child temperament or cognitive processing and development that also influence the 
relationship between interparental aggression and child disturbance.

The Role of Cognitive Appraisal. Previous work by Rutter (1983) supports the notion that children's cognitions can play a role in the way in which interparental aggression impacts child adjustment. Rutter asserts that a child's cognitive appraisal of stressful events may influence how the events are experienced by the child, as well as the child's subsequent response to the events. "Cognitive appraisal" refers to the child's processing of an event such that he or she comes to some understanding of what has happened-- giving the event meaning and establishing beliefs about the event. According to Rutter, the key elements of one's cognitive appraisal include both the perception of the meaning of stressful events and the anticipation of what can be done about them. Rutter concludes that the long-term impact of chronic stress situations may be determined by how the stressors are dealt with, which may be a function of one's conceptions regarding the situation.

The present research is concerned with the potential deleterious effects of interparental aggression on children and children's processing of the incidents. Cummings et al. (1989) provide evidence demonstrating that exposure to interparental aggression is experienced as stressful for most children. In accord with Rutter (1983), it is hypothesized then, that the effects of ongoing interparental 
aggression on children's adjustment may be influenced by children's cognitive appraisal of parents' conflict, which may be experienced as a chronically stressful event.

In their review of the literature on interparental aggression and children's adjustment, Grych and Fincham (1990) discuss the role of children's cognitive appraisal. These authors state that there are a variety of factors that influence the child's efforts to understand the conflict: affect, causal attributions, attributions of responsibility and blame, and efficacy expectations (i.e., children's beliefs in their ability to cope with the conflict). When an interparental conflict occurs, initially the child is said to undergo primary appraisal (Lazarus \& Folkman, 1984) in which the child senses the degree of threat or challenge present. Grych and Fincham (1990) suggest that if the conflict is perceived as negative, significant, or selfrelevant, further processing usually will occur. During secondary processing, the child will try to determine why the conflict is occurring, who is responsible for the difficulty, and whether the child will be able to cope with the conflict (i.e., causal, responsibility, and efficacy attributions, respectively).

Kurdek and Berg (1987) directly assessed the relationship between cognitive appraisal and children's adjustment by examining children's beliefs about parental divorce. The authors claim that children often construct 
problematic beliefs about divorce (e.g., "My parents would probably still be living together if it weren't for me"), and such beliefs are thought to impact children's adjustment. Kurdek and Berg have developed an objective measure of children's views of parental divorce, called the Children's Beliefs About Parental Divorce Scale (CBAPS).

These authors found that problematic beliefs about parental divorce were related to self-reported maladjustment. Specifically, children's total scores showed that problematic beliefs were related to high anxiety, low self-concept, and low social support (e.g., reflecting whether the child discusses his or her feelings with others) as indicated on measures completed by the children. Notably, problematic beliefs were not significantly related to both parent and teacher ratings of behavior problems. This finding may reflect the fact that the authors used a nonclinic sample and therefore the children's difficulties were less overt. Kurdek and Berg point out that even in their nonclinic sample, there were high levels of problematic beliefs as well as self-reported distress in the children. The authors emphasize the importance of including children as sources of information about their own intrapersonal thoughts and feelings.

The research of Kurdek and Berg (1987) provides essential information regarding children's adjustment vis-avis their beliefs about divorce. It may also be useful to 
examine children's beliefs about interparental aggression and determine whether such cognitive appraisals are related to children's adjustment. It is also conceivable that other mechanisms, such as children's coping responses, may be operative as well.

In summary, the notion that how children appraise and come to understand stressful events impacts their adjustment has been supported in the literature. More research is needed to further ascertain whether children construct problematic beliefs about their parents' conflicts, and whether such beliefs are related to children's maladjustment. Further, it is possible that children's cognitions about interparental aggression may be related to how they cope with such incidents.

The Role of Coping. Another area of study has focused on children's coping responses in the face of stressful events. Previous research (Compas, Malcarne, \& Fondacaro, 1988; Jose, D'Anna, \& Cafasso, 1992; Spivack \& Shure, 1982, 1985) has shown that children's coping is related to adjustment along a number of variables. For example, Jose et al. have investigated the relationship between children's coping with stressful events and adjustment using the Children's Coping Strategies Scale (CCSS; Jose, 1991). The authors found that adaptive coping strategies, such as the use of social supports, can moderate the effects of stress on adjustment outcome measures. 
The present research is concerned with how children's coping responses to interparental aggression, in particular, relate to their adjustment, and whether children's cognitive appraisal of the conflict may be related to the coping strategies children chose. Researchers (Compas, 1987; Grych \& Fincham, 1990; Rutter, 1983) have suggested that children's cognitive appraisal influences their coping responses, which in turn, impact on children's adjustment. Children's evaluation of and beliefs about the observed interparental aggression may influence coping behaviors chosen in response to the conflict. Compas, for example, states that children's responses to marital conflict are likely to be influenced by their beliefs in their ability to cope with the conflict. In summary, it is possible that children who construct problematic beliefs about interparental conflict choose less effective coping strategies that, in turn, contribute to poorer adjustment.

Grych and Fincham (1990) point out that the link between children's cognitive processing of interparental aggression and children's coping responses requires further investigation. The present study examines whether the effects of interparental aggression on child adjustment are moderated by children's cognitive processing and coping responses pertaining to the conflict. It is suggested that children exposed to interparental aggression may construct problematic or nonproblematic beliefs about the conflict and 
such beliefs may be related to the effective or ineffective coping strategies used.

In summary, the results of previous research suggest that children's cognitive appraisal of, and their coping responses to, interparental aggression may be important moderating variables in the interparental aggression-child adjustment relationship. Other moderator variables, such as age and gender of the child, may have an effect on the relationship between observed conflict and child adjustment as well. Previous research addressing the effects of age and gender will be reviewed below. Age and Gender as Moderator Variables

Age of the Child. The occurrence of interparental conflict, ranging from verbal hostility to physical aggression, and its impact on children's adjustment has been examined across a wide age range. Jouriles, Pfiffner, and O'Leary (1988) found that overt verbal marital conflict correlated positively with observations of toddler conduct problems. A number of studies have also found a relationship between marital conflict (verbal and physical) and child problems in school-age children (Jouriles et al., 1989; Shaw \& Emery, 1987; Wolfe, Zak, Wilson, \& Jaffe, 1986).

Specifically, these investigations have found effects of child behavior problems and difficulties in children's social competence as measured by the CBC (Achenbach \& 
Edelbrock, 1983) and the Perceived Competence Scale (PCS; Harter, 1982, Harter \& Pike, 1984). Jouriles et al. (1989) also found that physical marital aggression was related to child difficulties (conduct disorder, personality disorder, and inadequacy-immaturity) at clinical levels as measured by the Behavior Problem Checklist (Quay \& Peterson, 1979).

Interparental verbal conflict has also been found to be related to adolescents' level of cognitive and social competence as perceived by the adolescents themselves and as indicated by teacher ratings (Long et al., 1987; Wierson, Forehand, \& McCombs, 1988). Long, Slater, Forehand, and Fauber (1988) also found a relationship between interparental verbal conflict and adolescents' level of anxiety-withdrawal and conduct disorder.

In summary, these studies demonstrate that the effects of verbal and physical interparental conflict are found across a wide age range and are manifested in a number of ways. It appears that there are no distinct categories of adjustment problems that are limited to a particular age group. Rather, difficulties ranging from deficits in perceived competence to conduct problems appear across a broad age range.

Gender of the Child. Grych and Fincham (1990) point out that early studies in this area reported that marital discord variables were more frequently associated with behavior problems in boys than in girls and that the effects 
on girls were thought to be more typically manifested in withdrawal or anxiety (Emery \& O'Leary, 1982; Porter \& O'Leary, 1980). However, more recent studies have reported significant associations between interparental aggression and internalizing and externalizing problems for both boys and girls (Johnson \& O'Leary, 1987; Long et al., 1988). Grych and Fincham suggest that the difference between these two sets of literature may be attributable to the fact that the former authors examined other marital variables such as dissatisfaction and divorce, and not conflict, per se. When conflict is assessed directly it appears that a variety of adjustment difficulties arise for both boys and girls. Conclusions and Hypotheses

Although the relationship between interparental aggression and child adjustment problems has been thoroughly documented, researchers are just beginning to explore the mechanisms by which such conflict may influence child behavior. Children's understanding of the conflict and their coping responses to such stressful events may play a significant role in the impact on children's adjustment; however, these variables have thus far received little empirical investigation in the interparental aggression literature. The present study covers new ground in the study of interparental aggression by providing a more finetuned analysis of the potentially moderating effects of cognitive appraisal and coping on children's adjustment. 
Based on the findings of previous research (Compas, 1987; Grych \& Fincham, 1990; Kurdek \& Berg, 1987; Rutter, 1983), it was hypothesized that children's cognitive appraisal of their parents' conflict would be related to the ways in which children cope with the conflict. Problematic cognitive appraisal of parental conflict was expected to be associated with less effective coping strategies; both problematic cognitive appraisal and ineffective coping were hypothesized to be related to children's maladjustment. In contrast, those children exposed to high levels of aggression but who develop appropriate beliefs about the conflict and effective coping strategies, were expected to be relatively better adjusted than those children in highconflict homes who have greater problematic beliefs and report more ineffective coping strategies.

In a study of the relationship between adolescent functioning and perceptions of interparental conflict, Wierson et al. (1988) found that both parental report (particularly maternal) and adolescent report of the marital conflict were significantly related to adolescent cognitive and social functioning. Additional analyses revealed that adolescents' perceptions accounted for unique variance in their functioning, beyond that accounted for by parental report. In a similar vein, Kurdek and Berg (1987) found a significant relationship between children's problematic beliefs and child reports of adjustment, but not parent and 
teacher reports of adjustment. Because of the importance of including children as well as adults as sources of information about children's psychological functioning, the present study utilized multiple measures of interparental aggression and child adjustment, as perceived by both children and parents.

Middle school-aged children ages 11 to 15 years were used as subjects in this study for the following reasons. First, it was necessary to utilize children old enough to provide useful information on their parents' conflicts and comprehend questions asking them to report on their own thoughts and responses to parental conflict. Second, given the fact that the present research is investigating new links in the interparental aggression literature with regard to cognitive appraisal and coping, it was important to utilize an age range comparable to that used in previous studies (e.g., Compas et al., 1988; Fauber et al., 1990; Kurdek \& Berg, 1987).

Specific Hypotheses. The hypotheses listed below were tested by first using children's report of interparental aggression, cognitive appraisal, coping, and adjustment and subsequently, by using parents' report of the interparental aggression, children's report of cognitive appraisal and coping responses, and parents' report of their children's adjustment. The hypothesized main effects and interaction effects are displayed in Figure 1. 
1. High levels of interparental aggression were expected to be associated with poorer child adjustment (main effect of conflict: Hypothesis \# 1).

2. Problematic cognitive appraisal of the conflict was expected to be related to poor child adjustment (main effect of cognitive appraisal: Hypothesis \#2).

3. Children from homes with high levels of interparental conflict who have problematic cognitive appraisal were expected to have poorer adjustment. Children from homes with high levels of interparental conflict but who have less problematic cognitive appraisal were expected to have relatively better adjustment (conflict by cognitive appraisal interaction: Hypothesis \# 3).

4. Poor coping strategies were expected to be related to poor child adjustment (main effect of coping: Hypothesis \# 4).

5. Children from homes with high levels of interparental conflict who have poor coping strategies were expected to have poorer adjustment. Children from homes with high levels of interparental aggression but who have effective coping strategies were expected to have relatively better adjustment (conflict by coping interaction: Hypothesis \# 5).

6. Cognitive appraisal and coping were expected to be related such that problematic cognitive appraisal would be associated with poor coping strategies (cognitive appraisal 
and coping correlation: Hypothesis \# 6). 


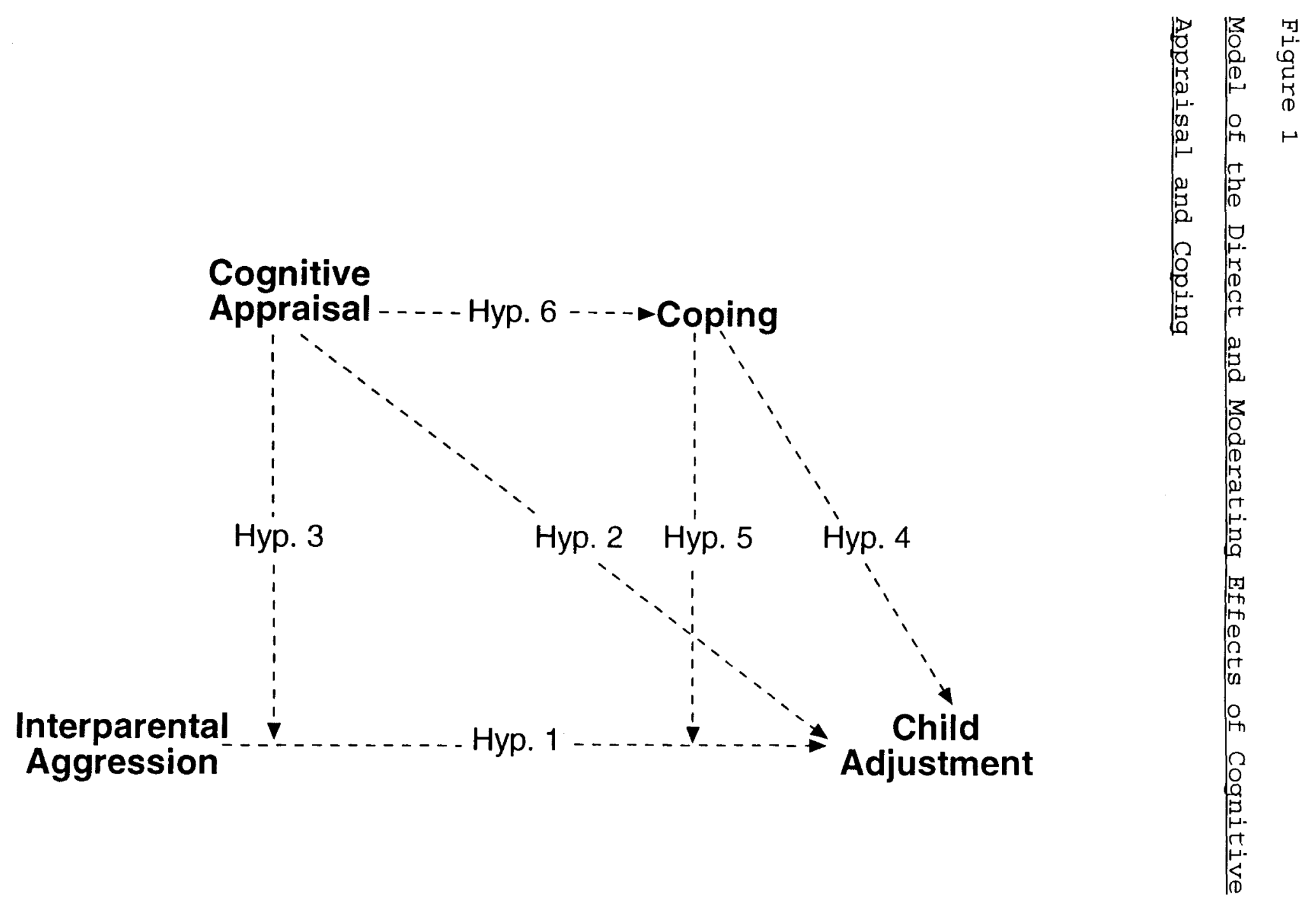


CHAPTER II

METHOD

\section{Subjects}

Subjects were 113 children and 45 parents recruited from seven school districts in a large midwestern city. The children were drawn from 6th-, 7th-, and 8th-grade classrooms in public elementary schools and ranged in age from 11 to 15 years (modal age $=12$ years old). The subjects were of ethnically diverse backgrounds, with $29 \%$ Caucasian, $25 \%$ African-American, $20 \%$ Hispanic, $8 \%$ AsianAmerican, $6 \%$ Indian children, and $7 \div$ of the subjects indicated that they were biracial or from other racial or ethnic groups. Complete demographic information is provided in Table 1. Subjects' socioeconomic status covered a broad range, with family incomes spanning from the 0-\$5,000 category to the $\$ 71,000-80,000$ annual income category (mean income group $=\$ 21,000-30,000)$. The distribution of family structure in the sample included $31 \%$ divorced families. Of the total sample, 76 \% parent respondents were the child's natural mother. Many of the respondent's partners in the study were the child subject's natural parent (56\%) or step-, or adoptive parent $(20 \%)$, most of whom were living in the home. 
Table 1

Demographic Characteristics of Sample

Characteristic--Child Subjects Percentage (Frequency)

Racial/Ethnic Group

Caucasian

African-American

Hispanic

Asian-American

Indian

Biracial/other

Missing data

Gender

Female

Male

Missing data

Grade

Sixth

Seventh

Eighth

Missing data

Age

11

12

13

14

15

Missing data

$$
\begin{aligned}
& 29 \circ(\mathrm{n}=33) \\
& 25 \div(\mathrm{n}=28) \\
& 20 \div(\mathrm{n}=23) \\
& 8 \div(\mathrm{n}=9) \\
& 6 \div(\mathrm{n}=7) \\
& 7 \%(\mathrm{n}=8) \\
& 5 \%(\mathrm{n}=5)
\end{aligned}
$$

$$
\begin{aligned}
56 \div(\mathrm{n}=63) \\
40 \div(\mathrm{n}=45) \\
4 \div(\mathrm{n}=5)
\end{aligned}
$$

$$
\begin{aligned}
67 \%(\mathrm{n}=76) \\
18 \div(\mathrm{n}=20) \\
13 \div(\mathrm{n}=15) \\
2 \%(\mathrm{n}=2)
\end{aligned}
$$

$$
\begin{aligned}
& 27 \div(\mathrm{n}=30) \\
& 42 \%(\mathrm{n}=47) \\
& 18 \div(\mathrm{n}=21) \\
& 9 \div(\mathrm{n}=11) \\
& 2 \div(\mathrm{n}=2) \\
& 2 \%(\mathrm{n}=2)
\end{aligned}
$$

School

$\begin{array}{lr}1 & 20 \div(\mathrm{n}=23) \\ 2 & 19 \div(\mathrm{n}=22) \\ 3 & 8 \div(\mathrm{n}=9) \\ 4 & 4 \div(\mathrm{n}=4) \\ 5 & 19 \div(\mathrm{n}=21) \\ 6 & 13 \div(\mathrm{n}=15) \\ 7 & 17 \div(\mathrm{n}=19)\end{array}$

Note.---Corresponding percentages and frequencies may not be identical for each variable due to rounding. 
Table 1 (cont.)

Income

$0-\$ 5,000$

$\$ 6,000-10,000$

$\$ 11,000-20,000$

$\$ 21,000-30,000$

$\$ 31,000-40,000$

$\$ 41,000-50,000$

$\$ 51,000-60,000$

$\$ 71,000-80,000$
$7 \%(\mathrm{n}=3)$
$18 \%(\mathrm{n}=8)$
$18 \div(\mathrm{n}=8)$
$15 \div(\mathrm{n}=7)$
$11 \div(\mathrm{n}=5)$
$18 \div(\mathrm{n}=8)$
$11 \div(\mathrm{n}=5)$
$2 \div(\mathrm{n}=1)$

$31 \div(n=14)$

Divorced

$$
\begin{aligned}
& 76 \div(\mathrm{n}=34) \\
& 20 \div(\mathrm{n}=9) \\
& 4 \div(\mathrm{n}=2)
\end{aligned}
$$

Partner's Relationship to Child

Natural Father

Step-father

$40 \div(\mathrm{n}=18)$

Natural Mother

$18 \div(\mathrm{n}=8)$

$16 \div(\mathrm{n}=7)$

Adoptive Parent

$2 \div(\mathrm{n}=1)$

Other (including foster care and non-marital stepparents)

$24 \div(\mathrm{n}=11)$

Respondent's Relationship to Partner

Spouse Living in Home

Significant Other in Home

$49 \div(\mathrm{n}=22)$

Former Spouse not in Home $18 \%(n=8)$

$20 \div(\mathrm{n}=9)$

other (including significant other not in home)

$13 \div(\mathrm{n}=6)$

Note.---Corresponding percentages and frequencies may not be identical for each variable due to rounding. 
$\underline{\text { Procedures }}$

Students in 6 th-, 7 th-, and 8 th-grade regular education classrooms at 7 public elementary schools were asked to participate in this research project. Each student was given a letter that briefly described the study and asked the parents to give written permission to allow their child to participate. Written child consent to participate was also requested. The letter explained that the parents would also be asked to complete a questionnaire that would be mailed to them (with return postage paid) and that their child would be given a questionnaire during school. (Copies of the parent letter and permission form, child questionnaire, and parent questionnaire are presented in Appendices $A, B$, and $C$, respectively.)

Those students who participated were administered the child questionnaire in small groups so that questions were readily addressed and so that proper completion of the measures was assured. For those parents who agreed to participate, a parent questionnaire was mailed to them with a self-addressed, postage-paid envelope. Those parents who failed to return the questionnaire within 3 weeks of the mailing were contacted by telephone and requested to complete and return the questionnaire.

\section{Measures}

Instructions and Demographic Information Form. The child subjects were asked to give basic information about 
their school, grade, birthdate, ethnic background, age, gender, hobby, and favorite T.V. program. The parent demographic form asked for basic information and assessed level of income and family structure. Those families that had more than one child in 6th-, 7th-, or 8 th-grade were asked to allow only the eldest child to participate.

Because previous research has shown that level of conflict appears to be a better predictor of child adjustment than variations in family structure (Bishop \& Ingersoll, 1989; Long, 1986), no exclusionary criteria regarding family structure were used for participation in the study. The purpose of the present study was to examine how children are affected by observing aggressive interactions between parents, as defined by the child's natural or adoptive parent interacting with the other natural parent (currently in the home or estranged from the other parent), step-parent, or parent's significant other. Using this definition allowed for broad participation in the study and potentially enhanced generalizability of the present findings.

The child subjects were told that the following questionnaire involved answering questions about children and their families in order to better understand the thoughts and feelings of children their age. Children were encouraged to respond openly and confidentially was assured. These subjects were directed to answer the questions 
regarding "parents" by considering either their own parents (natural or adoptive), their parent and step-parent, or parent and parent's significant other. Children who indicated that their parent was single at this time, were asked to answer the questions by recalling the interactions of their own parents. In completing the questionnaire, parents were asked to consider their partner or former partner and to indicate the specific type of relationship.

Interparental Aggression. In order to assess frequency and intensity of conflict between parents, the Conflict Tactics Scale (CTS; Straus, 1979) was completed by the parent subjects. There are 19 items on the CTS on which respondents rate the frequency of occurrence of various types of verbal and physical aggression and attempts at reasoning used by both partners. The CTS is comprised of three scales. The Verbal Aggression scale refers to the use of verbal and nonverbal acts that symbolically hurt another person. The Violence scale assesses the use of physical force against the other and the Reasoning scale reflects use of induction and discussion to resolve disagreements.

Children were asked to complete a modified version of the CTS in order to assess their perceptions of frequency and intensity of the parental aggressive interactions. The children's version utilized modified language (e.g., "Discussed an issue calmly" was changed to "Talked about it") and included items from each of the three scales, 
Reasoning (three items), Verbal Aggression (four items), and Violence (six items). Three of the more severe Violence items (e.g., "Used a knife or fired a gun") were excluded from the children's questionnaire in order to avoid the potential of upsetting or alarming some of the children unduly.

It has been shown that the CTS has adequate internal consistency (Straus, 1979) and correlates with a variety of hypothesized predictors of marital aggression (Straus et al., 1980). To test the internal consistency of the measures used in the present study, alpha coefficients were computed for the parent-version of the CTS (Cronbach's alpha $=.85$ ) and for the child-version of the CTS (Cronbach's alpha $=.77)$.

Cognitive Appraisal. Children's beliefs about their parents' conflicts were measured using a modified version of the Children's Beliefs About Parental Divorce Scale (CBAPS; Kurdek \& Berg, 1987). The CBAPS is a 36 -item scale comprised of statements that tap children's thoughts and beliefs about their parents' divorce as they pertain to six different dimensions: peer ridicule and avoidance, paternal blame, fear of abandonment, maternal blame, hope of reunification, and self-blame.

In the present study the instructions were modified in order to assess children's beliefs about parental conflict rather than parental divorce. Some items were also changed 
so that the language used referred to interparental

conflict. The modified CBAPS included 21 yes/no questions that reflect problematic beliefs (e.g., "My parents would probably not be fighting if it weren't for me") and 15 yes/no questions that represent non-problematic beliefs (e.g., "I feel my parents still like me"). This scale was scored such that a high score indicates greater problematic beliefs and fewer non-problematic beliefs endorsed by the subject (i.e., non-problematic beliefs were reverse scored).

Following Kurdek and Berg (1987), the items were grouped into six subscales. The individual items comprising each subscale are presented in Appendix D. The subscales used in the present research included (Cronbach's alpha values are noted in parentheses): peer concerns (.55), paternal blame (.79), fear of abandonment (.59), maternal blame (.73), hope of resolution (.26), and self-blame (.47). The internal consistency of the subscales in the present study was found to be slightly lower than that reported by the authors (range $=.54$ to $.78, \underline{\mathrm{M}}=.70$ ).

Coping. Children's coping strategies were assessed using a modified version of the Children's Coping strategies Scale (Jose, 1991). The CCSS is comprised of a list of coping items (such as "I cry" and "I go off by myself") in which the child indicates how he or she typically responds to stressful episodes. For each item, the child is to state how frequently he or she engages in that particular behavior 
according to a five-point scale (ranging from "never" to "a lot").

In the present study, the instructions of the CCSS were modified such that children were directed to indicate how frequently they engage in each behavior in response to their parents' disagreements or fights. The items were coded in such a way that poor coping was defined as high ineffective strategies scores and low effective strategies scores (i.e., effective strategies items were reverse scored). The categorization of coping strategies was based on Jose's (1991) subscale groupings. Effective strategies in the present research included items in the following subscales (Cronbach's alpha values are noted in parentheses): social support (.74), change situation (.66), change self (.76), and distraction (.46); the ineffective strategies subscales included aggression (.76), self-destruction (.71), avoidance (.36), and ventilation (.63). The individual items that comprise each subscale are presented in Appendix D. The author of the CCSS (in Jose, Cafasso, \& D'Anna, in press) reported somewhat higher levels of internal consistency for slightly different subscale groupings used in a recent study (range $=.50$ to $.84, \underline{M}=70)$.

Child Adjustment. The Child Behavior Checklist (CBC; Achenbach \& Edelbrock, 1983) was utilized to assess the level of children's general emotional and behavioral problems. The CBC provides a parental rating of the extent 
of a child's behavior problems and yields scores on a number of problem scales as well as a total problem score.. Raw scores for the total problem behavior scale were used in this research. The authors (Achenbach \& Edelbrock, 1983) have presented extensive evidence demonstrating the reliability and validity of the scale. A high level of internal consistency was found for the use of the problem scale in the present study (Cronbach's alpha $=.95$ ).

Children completed the externalizing subscale of the Youth Self-Report (YSR), which is comprised of 37 items assessing delinquent and aggressive behavior. The externalizing subscale of 37 items was constructed by combining all of the items from both the delinquent and aggressive subscales for both males and females and eliminating repeated items. Because the normative data were originally derived from a slightly older population (ages 11-18), raw scores were used in the present study in place of T-scores. Reliability and validity data for the YSR have been reported by the authors (Achenback \& Edelbrock, 1987). Cronbach's alpha for the YSR externalizing subscale in the present research was found to be .93 .

The parent version of the Self-Perception Profile for Children (SPP; Harter, 1982, 1985) was used to assess parents' views of their children's competence in a variety of areas. The original child version of the SPP is a 36 item scale tapping competence in scholastic, social, 
athletic, appearance, conduct, and global self-worth domains. Psychometric properties of the SPP have been presented by Harter $(1982,1985)$. The parent version used in the present study is a 15 -item adaptation of the teacher version that includes three items from each of the following domains: Scholastic, social, athletic, appearance, and conduct. Child-report data were also obtained by having the children complete the six-item Global self-worth subscale of the SPP in order to assess children's perceptions of their own self-worth and general well-being. Cronbach's alpha was .82 for the parent version of the SPP, and .66 for the children's use of the Global Self-worth subscale used in the present research.

The Children's Depression Inventory (CDI; Kovacs, 1981) was used to measure self-reported depressive symptoms in children. The CDI is comprised of 27 items for which children chose one of three choices that best describes their experiences during the previous two weeks. Reliability and validity data have been presented for this measure (Kazdin, 1981; Kazdin, French, Unis, Esveldt-Dawson, \& Sherick, 1983). High internal consistency was found for the CDI in the present study as well (Cronbach's alpha = $.88)$.

\section{Statistical Analysis}

Multiple regression analyses were performed for both the child-report and parent-report data. The analyses were 
conducted to determine whether there were main effects of conflict, main effects of cognitive appraisal, main effects of coping, conflict by appraisal interactions, and conflict by coping interactions on the dependent adjustment variables. The child data were initially analyzed separately and included the child-reported conflict, cognitive appraisal, and coping variables, and the childreported dependent variables: self-worth, externalizing behavior, and depression $(n=113)$.

Subsequent analyses that included the parent data utilized the parent-reported conflict variable, the children's report of cognitive appraisal and coping, and the parent-reported adjustment variables (child behavior problems and perceived competence). Only those subjects for whom both parent and child data were available were included in this set of analyses ( $n=45$ pairs).

For all analyses, the variables were defined as follows :

1. High scores on the conflict scale (for both children and parents) indicated more frequent and intense interparental aggression.

2. High scores on the cognitive appraisal measure (child report) indicated more problematic beliefs about the conflict.

3. High scores on the coping measure indicated greater use of poor coping strategies and less frequent use of 
effective coping strategies.

4. Poor adjustment was defined as high scores on the externalizing behavior scale (child report), high scores on the depression inventory (child report), low scores on the self-worth scale (child report), high scores on the behavior problem scale (parent report), and low scores on the perceived competence scale (parent report).

Following the main analyses, additional regressions were performed to determine whether there were significant main effects and interactions with conflict scores using the subscales of the cognitive appraisal and coping measures. Pearson correlations were also computed to determine whether there was a significant association between cognitive appraisal and coping (Hypothesis \# 6). 


\section{CHAPTER III}

RESULTS

\section{Sample Characteristics}

Summary statistics including the means and standard deviations for the parent and child variables are presented in Table 2. (Due to variations in scoring procedures, the raw score means are not directly comparable to normative data.) It was noted that the present sample scores slightly higher than normative samples on measures of conflict (child and parent report), problematic beliefs, ineffective coping, problematic and externalizing behavior, depression, competence, and self-worth as reported by the authors.

The level of interparental conflict indicated by the child subjects in this study is summarized here by reporting the percentage of subjects endorsing each verbal aggression and physical aggression item (i.e., percentage reported to have observed the action one or more times over the past year). The verbal aggression items included stomped out of house $(36.3 \%)$, insulted/swore $(45.1 \%)$, threatened to hit/hurt (12.4\%), and hurt feelings (49.5\%). The physical aggression, or violence scale, items included threw something at other $(22.2 \%)$, pushed/shoved (17.1\%), slapped $(17.6 \%)$ kicked/hit $(13.4 \%)$, beat up ( $8 \%)$, and hit or 
Table 2

Means and Standard Deviations for Parent and Child Variables Variable Mean (S.D.)

Conflict--Parent

Conflict--Child

Cognitive Appraisal--Child

Coping--Child

Problem Behavior--Parent

Competence--Parent

Self-Worth--Child

Externalizing Behavior--Child

Depression--Child
$43.08 \quad(14.28)$
$25.77 \quad(5.72)$
$6.85(4.30)$
$87.17(10.70)$
$155.48 \quad(22.80)$
$49.40 \quad(6.00)$
$17.52 \quad(3.59)$
$18.80(12.58)$
$36.16 \quad(7.56)$

Note.-- -All values represent raw scores. $n=45$ for parent-report variables and $\mathrm{n}=113$ for child-report variables. 
attempted to hit with object (16.8).

On the parent version of the CTS, the verbal aggression items included insulted/swore (57.8\%), refused to talk $(53.3 \%)$, stomped out of house (37.8\%), said something to spite other $(53.3 \%)$, and threatened to hit/hurt $(20 \%)$. The items on the violence scale included threw/kicked something $(26.7 \%)$, threw something at other $(22.2 \%)$, pushed/grabbed (20\%), slapped (17.8\%), kicked/hit $(13.3 \%)$, hit or attempted to hit with object $(13.3 \%)$, beat up (4\%), choked ( $8.9 \%)$, threatened with knife or gun (2\%), and used a knife or gun ( $0 \%)$. Normative data provided by the author of the CTS (Straus, 1990) indicate a range from $12 \%$ to $16 \%$ of respondents reporting some level of interparental physical aggression, whereby younger couples were found to report more violence.

In order to estimate potential differences between the sample of parents who participated in the study and those who failed to return the questionnaires, the respective child participants were compared along the demographic, independent, and dependent variables. Results showed that the group of children whose parents participated $(n=45)$ did not differ from those whose parents did not participate ( $\mathrm{n}=68$ ) along a number of variables, including school, grade, race/ethnicity, gender, conflict, coping, self-worth, externalizing behavior, and depression. Differences were found between the two groups for the age of child and 
beliefs variables, such that children whose parents participated were slightly older $(\underline{\underline{M}}=12.42)$ than those children whose parents did not participate $(\underline{\underline{M}}=12.00)$, $\underline{t}(109)=-2.23, \underline{p}<.05$. Children whose parents participated were also found to have slightly lower problematic beliefs scores $(\underline{M}=5.86)$ than the remaining Children $(\underline{\underline{M}}=7.51), \underline{t}(111)=2.02, \underline{\underline{p}}<.05$.

Preliminary regression analyses including the demographic variables revealed no significant effects of the parent-reported demographic variables on the outcome measures. Step-wise regression analyses performed on the child data revealed a significant effect of school on selfworth, $\underline{B}=.36, \mathrm{R}^{2}$ change $=.13, \underline{\mathrm{p}}<.001$, and a significant effect of age on externalizing behavior, $\underline{B}=.285, R^{2}$ change $=.08, \underline{p}<.05$. These results revealed that older children tended to report more externalizing behavior and that students in one of the seven schools that participated tended to report higher levels of self-worth. No significant effects were found for gender or race/ethnicity. Due to the small number of subjects in each of the individual demographic groups, no further analyses were conducted on the demographic variables. The effects of the demographic variables were controlled by entering these variables as covariates in subsequent regression analyses. Correlation Analyses

Pearson correlations were computed among the nine child 
and parent variables, including child-reported conflict, parent-reported conflict, cognitive appraisal (child report), coping (child report), problem behavior (parent report), competence (parent report), self-worth (child report), externalizing behavior (child report), and depression (child report).

A number of variables were found to be significantly correlated. The results of the correlation analyses are displayed in the correlation matrix presented in Table 3. of particular note for the present research was the finding that children's cognitive appraisal scores were found to be significantly related to children's coping strategies scores, $r=.226, \underline{p}<.05$, (Hypothesis \# 6). That is, children who tended to endorse problematic beliefs about their parents' conflicts also tended to report greater use of ineffective coping strategies.

Analyses of Child Data

Multiple regression analyses were performed on the child data to determine whether there were main effects of conflict, cognitive appraisal, and coping, and to assess whether there were significant conflict $\mathrm{X}$ cognitive appraisal and conflict $\mathrm{x}$ coping interactions in predicting the child-reported dependent adjustment measures (selfworth, externalizing behavior, and depression). In order to control for effects of the demographic variables (i.e., school, grade, gender, and race), these variables were 
Table 3

Correlation Matrix for Parent-Report and Child-Report

Variables with Alpha Coefficients

\begin{tabular}{|c|c|c|c|c|}
\hline & $\begin{array}{c}\text { Competence } \\
\text { - - Parent }\end{array}$ & $\begin{array}{l}\text { Self-Worth } \\
\text {--Child }\end{array}$ & $\begin{array}{c}\text { Ext. Beh. } \\
\text {--Child }\end{array}$ & $\begin{array}{l}\text { Depress. } \\
\text {--Child }\end{array}$ \\
\hline $\begin{array}{l}\text { Conflict } \\
\text {--Parent }\end{array}$ & -.258 & -.179 & .175 & .260 \\
\hline $\begin{array}{l}\text { Conflict } \\
- \text { - Child }\end{array}$ & -.121 & $-.230 *$ & $.444 \star \star$ & $.402 * *$ \\
\hline $\begin{array}{l}\text { Cog. App. } \\
\text {--Child }\end{array}$ & -.322 & $-.375 * \star$ & $.370 \star *$ & $.517 * *$ \\
\hline $\begin{array}{l}\text { Coping } \\
\text {--Child }\end{array}$ & .067 & -.309 & $.457 \star \star$ & $.444 * \star$ \\
\hline $\begin{array}{l}\text { Prob. Beh. } \\
\text { - -Parent }\end{array}$ & $-.299 *$ & .029 & .225 & .187 \\
\hline $\begin{array}{c}\text { Competence } \\
\text {--Parent }\end{array}$ & $(.82)$ & .244 & -.088 & -.288 \\
\hline $\begin{array}{l}\text { Self-Worth } \\
\text {--Child }\end{array}$ & & $(.66)$ & $-.233 *$ & $-.579 * *$ \\
\hline $\begin{array}{l}\text { Ext. Beh. } \\
-- \text { Child }\end{array}$ & & & $(.93)$ & $.658 * *$ \\
\hline $\begin{array}{l}\text { Depress. } \\
\text { - - Child }\end{array}$ & & & & $(.88)$ \\
\hline
\end{tabular}

Note.--Alpha coefficients are marked in parentheses. $\star \mathrm{P}<.05$

$\star * \underline{p}<.01$ 
Table 3 (cont.)

\begin{tabular}{|c|c|c|c|c|c|}
\hline & $\begin{array}{l}\text { nflict } \\
\text { - Parent }\end{array}$ & $\begin{array}{l}\text { Conflict } \\
\text {--Child }\end{array}$ & $\begin{array}{l}\text { Cog. App. } \\
\text {--Child }\end{array}$ & $\begin{array}{l}\text { Coping } \\
\text {--Child }\end{array}$ & $\begin{array}{l}\text { Prob.Beh. } \\
\text { - - Parent }\end{array}$ \\
\hline $\begin{array}{l}\text { Conflict } \\
- \text { - Parent }\end{array}$ & $(.85)$ & .286 & $.412 \star \star$ & .194 & $.491 \star \star$ \\
\hline $\begin{array}{l}\text { Conflict } \\
- \text {-Child }\end{array}$ & & $(.77)$ & $.402 \star \star$ & $.291 * *$ & .094 \\
\hline $\begin{array}{l}\text { Cog. App. } \\
- \text {-Child }\end{array}$ & & & $(.76)$ & .226 * & .107 \\
\hline $\begin{array}{l}\text { Coping } \\
- \text {-Child }\end{array}$ & & & & $(.57)$ & .057 \\
\hline $\begin{array}{l}\text { Prob. Beh. } \\
\text {--Parent }\end{array}$ & & & & & $(.95)$ \\
\hline
\end{tabular}

Note.--Alpha coefficients are marked in parentheses. $\star \underline{\mathrm{p}}<.05$

$\star * \underline{p}<.01$ 
entered first into the equation as covariates in each analysis. Subsequently, each main effect was entered into the equation followed by the interaction term (Cohen \& Cohen, 1983).

Cognitive Appraisal. The results of the analyses involving the cognitive appraisal variable are summarized in Table 4. The results revealed a significant negative main effect of cognitive appraisal on self-worth, $\underline{B}=-.396, R^{2}$ change $=.131, \underline{p}<.001 . \quad$ (Note that all Beta weights reported reflect standardized values.) This finding indicates that children who endorsed more problematic beliefs (and fewer non-problematic beliefs) about their parents' conflicts tended to have lower self-worth scores (Hypothesis \# 2). The effect of conflict and the conflict $\mathrm{X}$ cognitive appraisal interaction were non-significant for the self-worth variable. The results for the externalizing behavior dependent variable revealed a significant main effect of conflict, $\underline{B}=.421, \mathrm{R}^{2}$ change $=.146, \underline{\mathrm{p}}<.001$, a main effect of cognitive appraisal, $\underline{B}=.23, \mathrm{R}^{2}$ change $=$ $.04, \underline{p}<.05$, and a non-significant conflict $x$ cognitive appraisal interaction. Significant main effects of cognitive appraisal, $\underline{\mathrm{B}}=.514, \mathrm{R}^{2}$ change $=.22, \underline{\mathrm{p}}<.001$, and conflict, $\underline{\mathrm{B}}=.214, \mathrm{R}^{2}$ change $=.033, \underline{\mathrm{p}}<.05$, and $\mathrm{a}$ non-significant conflict $\mathrm{x}$ cognitive appraisal interaction were found for depression.

These findings indicate that children in high-conflict 
Table 4

Summary of Regression Analyses for Child-Reported Conflict and Dependent Variables--Cognitive Appraisal (Beliefs)

\begin{tabular}{|c|c|c|c|c|c|}
\hline Step & Variable & Mult.R & $\mathrm{R}^{2}$ change & Beta & $\bar{F}$ \\
\hline \multicolumn{6}{|c|}{ Dependent Variable $=$ Self-Worth } \\
\hline$\overline{1}$ & Covariates & .337 & .114 & $\ldots$ & .977 \\
\hline 2 & Beliefs & .494 & .131 & -.396 & $2.264 * \star$ \\
\hline 3 & Conflict & .495 & $<.001$ & -.033 & 2.101 \\
\hline 4 & $\mathrm{~B} \times \mathrm{C}$ & .505 & .010 & .560 & 2.056 \\
\hline
\end{tabular}

Dependent Variable = Externalizing Behavior

\begin{tabular}{lccccc}
\hline 1 & Covariates & .345 & .119 &.-- & 1.031 \\
2 & Conflict & .515 & .146 & .421 & $2.527 *$ * \\
3 & Beliefs & .552 & .039 & .230 & $2.827 *$ \\
4 & C X B & .558 & .007 & .461 & 2.709
\end{tabular}

\begin{tabular}{|c|c|c|c|c|c|}
\hline \multirow[b]{2}{*}{$\overline{1}$} & \multicolumn{2}{|c|}{ Dependent Variable } & \multicolumn{2}{|c|}{$=$ Depression } & \multirow[b]{2}{*}{1.078} \\
\hline & Covariates & .352 & .124 & $\cdots$ & \\
\hline 2 & Beliefs & .577 & .209 & .519 & $3.486 * \star$ \\
\hline 3 & Conflict & .611 & .041 & .234 & $3.854 *$ \\
\hline 4 & $\mathrm{~B} \times \mathrm{C}$ & .621 & .013 & 1.220 & 3.774 \\
\hline
\end{tabular}

Note.--Covariates = school, grade, gender, and race.

"B X C" refers to the Beliefs by Conflict interaction effect.

$$
\begin{aligned}
& \star \mathrm{p}<.05 \\
& \star \star \mathrm{p}<.001
\end{aligned}
$$


homes reported greater externalizing problems and depression (Hypothesis \# I) and that children who tended to endorse more problematic beliefs also had higher externalizing and depression scores (Hypothesis \#2). Non-significant interaction effects were found for cognitive appraisal and conflict (contrary to Hypothesis \# 3).

Coping. The results of the analyses for the coping variable revealed a significant negative main effect of coping, $\underline{B}=-.315, \mathrm{R}^{2}$ change $=.077, \underline{\mathrm{p}}<.05$, on self-worth. The conflict and interaction effects were non-significant for the self-worth dependent variable. The results of the analyses for the coping variable are presented in Table 5. For the externalizing behavior variable, significant main effects were found for coping, $\underline{B}=.524, \mathrm{R}^{2}$ change $=.213, \underline{\mathrm{D}}$ $<.001$, and conflict, $\underline{B}=.294 ;$ the conflict $\mathrm{X}$ coping interaction was non-significant. Significant main effects were also found for coping, $\underline{\mathrm{B}}=.519, \mathrm{R}^{2}$ change $=.21, \underline{\mathrm{p}}<$ .001 , and conflict, $\underline{B}=.234, \mathrm{R}^{2}$ change $=.04, \underline{\mathrm{p}}<.05$, for the depression variable. The conflict $\mathrm{x}$ coping interaction was non-significant for depression.

In summary, the results of the analyses involving the coping variable revealed that children who reported greater use of ineffective coping strategies (and less usage of effective strategies) tended to have lower self-worth scores and higher externalizing and depression scores (Hypothesis \# 
Table 5

Summary of Regression Analyses for Child-Reported Conflict and Dependent Variables--Coping

\begin{tabular}{lllll}
\hline Step & Variable & Mult.R & $\mathrm{R}^{2}$ change & \\
\end{tabular}

\begin{tabular}{|c|c|c|c|c|c|}
\hline \multicolumn{6}{|c|}{ Dependent Variable $=$ Self-Worth } \\
\hline 1 & Covariates & .337 & .114 & $-\cdots$ & .977 \\
\hline 2 & Coping & .437 & .077 & -.315 & $1.648 *$ \\
\hline 3 & Conflict & .442 & .005 & -.079 & 1.570 \\
\hline 4 & $\mathrm{CXC}$ & .445 & .003 & .553 & 1.481 \\
\hline
\end{tabular}

Dependent Variable $=$ Externalizing Behavior

\begin{tabular}{lccccc}
\hline 1 & Covariates & .345 & .119 &.-- & 1.031 \\
2 & Coping & .576 & .213 & .524 & $3.476 * \star$ \\
3 & Conflict & .630 & .065 & .294 & $4.249 * \star$ \\
4 & C X C & .635 & .007 & .871 & 4.050
\end{tabular}

\begin{tabular}{|c|c|c|c|c|c|}
\hline \multicolumn{6}{|c|}{ Dependent Variable $=$ Depression } \\
\hline$\overline{1}$ & Covariates & .352 & .124 & $\cdots$ & 1.078 \\
\hline 2 & Coping & .587 & .220 & .514 & $3.676 * *$ \\
\hline 3 & Conflict & .615 & .033 & .214 & $3.926 *$ \\
\hline 4 & $C \times C$ & .615 & $<.001$ & .145 & 3.653 \\
\hline
\end{tabular}


4). The conflict $x$ coping interaction effects were nonsignificant for the dependent measures (contrary to Hypothesis \# 5).

\section{Subscale Exploratory Analyses}

Multiple regression analyses were performed using the subscales of the cognitive appraisal and coping measures. For each analysis, the covariates were entered first into the equation as control variables, after which the subscale term and the conflict variable were entered as main effects, followed by the conflict $x$ subscale interaction term. Selfworth, externalizing behavior, and depression were the dependent variables. Because of the exploratory nature of this set of analyses, these results should be interpreted with caution.

Cognitive Appraisal Subscales. The subscales of the cognitive appraisal measure included peer concerns, paternal blame, fear of abandonment, maternal blame, hope of resolution, and self-blame. The following significant main effects were found: Peer concerns had a significant effect on self-worth, $\underline{B}=-.306, \mathrm{R}^{2}$ change $=.085, \underline{\mathrm{p}}<.005$, and depression, $\underline{B}=.187, \mathrm{R}^{2}$ change $=.031, \underline{\mathrm{p}}<.05$; fear of abandonment had a significant effect on self-worth, $\underline{B}=$ $-.409, \mathrm{R}^{2}$ change $=.139, \underline{\mathrm{p}}<.001$, externalizing behavior, $\underline{\mathrm{B}}$ $=.419, \mathrm{R}^{2}$ change $=.146, \mathrm{p}<.001$, and depression, $\underline{\mathrm{B}}=$ $.541, \mathrm{R}^{2}$ change $=.244, \underline{\mathrm{p}}<.001$; maternal blame had a significant effect on externalizing behavior, $\underline{B}=.206, R^{2}$ 
change $=.032, \underline{\mathrm{p}}<.05$, and depression, $\underline{\mathrm{B}}=.234, \mathrm{R}^{2}$ change $=.041, \underline{p}<.05 ;$ hope of resolution had a significant effect on self-worth, $\underline{B}=-.253, \mathrm{R}^{2}$ change $=.058, \underline{\mathrm{p}}<.05$, externalizing behavior, $\underline{B}=.259, \mathrm{R}^{2}$ change $=.057, \underline{\mathrm{D}}<.01$, and depression, $\underline{\mathrm{B}}=.424, \mathrm{R}^{2}$ change $=.163, \underline{\mathrm{p}}<.001$; and self-blame had a significant effect on self-worth, $\underline{B}=$ $-.360, \mathrm{R}^{2}$ change $=.109, \underline{\mathrm{p}}<.001$, externalizing behavior, $\underline{\mathrm{B}}$ $=.216, \mathrm{R}^{2}$ change $=.038, \underline{\mathrm{p}}<.05$, and depression, $\underline{\mathrm{B}}=.378$, $\mathrm{R}^{2}$ change $=.12, \underline{\mathrm{p}}<.001$. None of the conflict $\mathrm{X}$ cognitive appraisal subscale interactions were significant.

Coping subscales. The coping subscales included social support, change situation, change self, distraction, aggression, self-destruction, avoidance, and ventilation. The following significant main effects were found: Distraction had a significant effect on self-worth, $\underline{B}=$ $-.249, \mathrm{R}^{2}$ change $=.047, \underline{\mathrm{p}}<.05 ;$ aggression had a significant effect on externalizing behavior, $\underline{B}=.599, \mathrm{R}^{2}$ change $=.292, \underline{\mathrm{p}}<.001$, and depression, $\underline{\mathrm{B}}=.468, \mathrm{R}^{2}$ change $=.179, \underline{p}<.001 ;$ self destruction had a significant effect on self-worth, $\underline{B}=-.27, \mathrm{R}^{2}$ change $=.062, \underline{\mathrm{p}}<.01$, externalizing behavior, $\underline{B}=.642, \mathrm{R}^{2}$ change $=.351, \underline{\mathrm{p}}<.001$, and depression, $\underline{\mathrm{B}}=.519, \mathrm{R}^{2}$ change $=.229, \underline{\mathrm{p}}<.001$; avoidance had a significant effect on depression, $\underline{B}=.193$, $\mathrm{R}^{2}$ change $=.031, \mathrm{p}<.05 ;$ and ventilation had a significant effect on externalizing behavior, $\underline{B}=.189, \mathrm{R}^{2}$ change $=$ 
$.029, \underline{p}<.05$

Significant conflict $\mathrm{X}$ coping subscale interactions were found. A significant conflict $\mathrm{X}$ avoidance interaction was found for externalizing behavior, $\underline{B}=-1.407, \mathrm{R}^{2}$ change $=.036, \underline{\mathrm{p}}<.05$, and depression, $\underline{\mathrm{B}}=-1.28, \mathrm{R}^{2}$ change $=$ $.03, p<.05$. A significant conflict $\mathrm{X}$ social support interaction was found for externalizing behavior, $\underline{B}=1.046$, $\mathrm{R}^{2}$ change $=.032, \mathrm{p}<.05$. The significant interaction effects are depicted in Figures 2 and 3.

Follow-up calculations performed in order to probe these interactions showed that higher social support scores were associated with lower externalizing scores for children in high-conflict homes, but relatively higher externalizing scores for children in low-conflict homes. Additionally, higher avoidance scores were associated with less externalizing and depression for children in high-conflict homes; children in low-conflict homes who had higher avoidance scores tended to score higher on externalizing and depression. It should be noted that children in the highconflict group had higher externalizing and depression scores overall, however.

Analyses of Parent Data

Multiple regression analyses were performed on the parent data to determine whether there were main effects of parent-reported conflict, and to assess whether there were significant conflict $\mathrm{X}$ cognitive appraisal and conflict $\mathrm{X}$ coping interactions in predicting the parent-reported 
Figure 2

Conflict by Avoidance Interaction Effects on Externalizing Behavior and Depression--Child Report
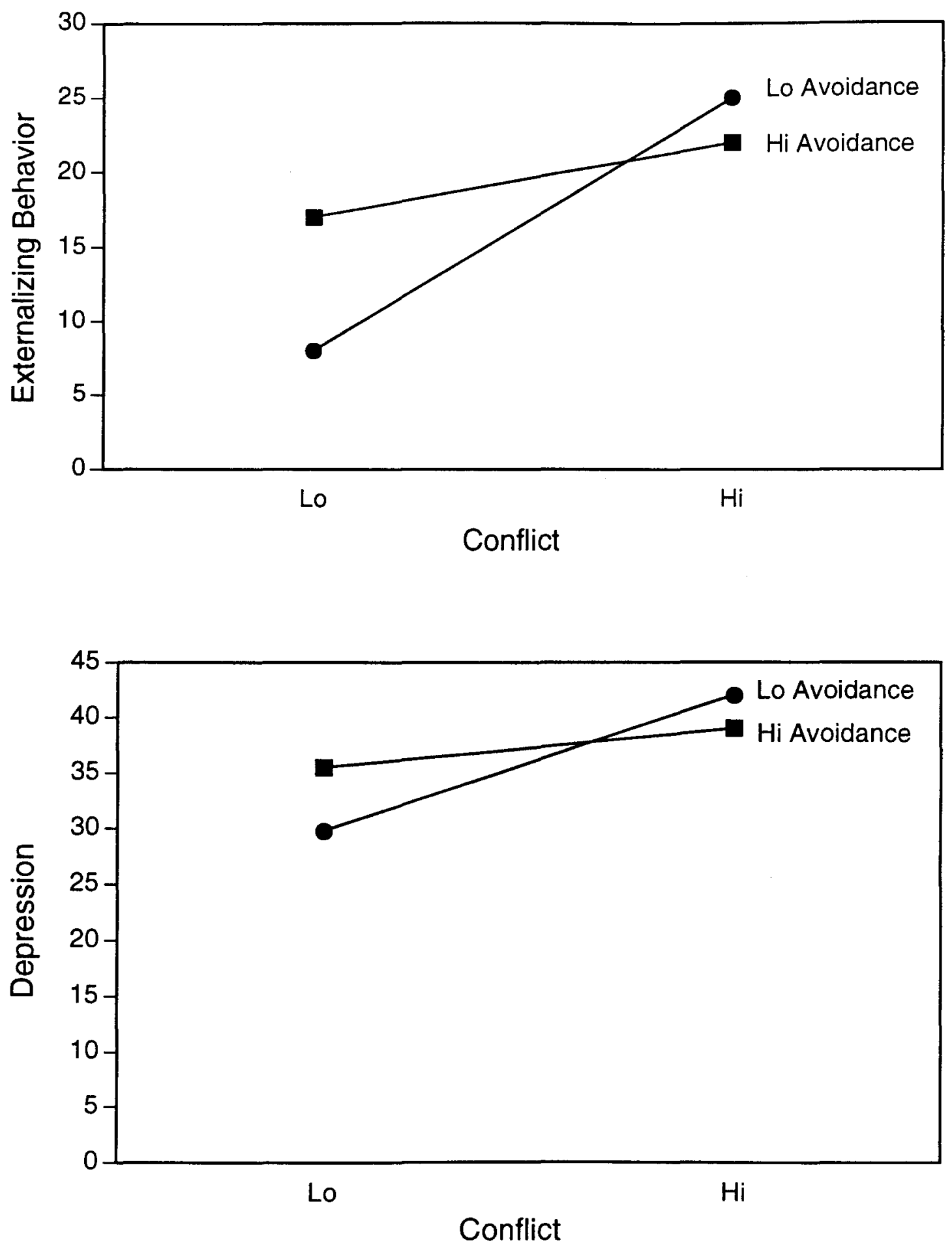
Figure 3

Conflict by Social Support Interaction Effect on

Externalizing Behavior--Child Report

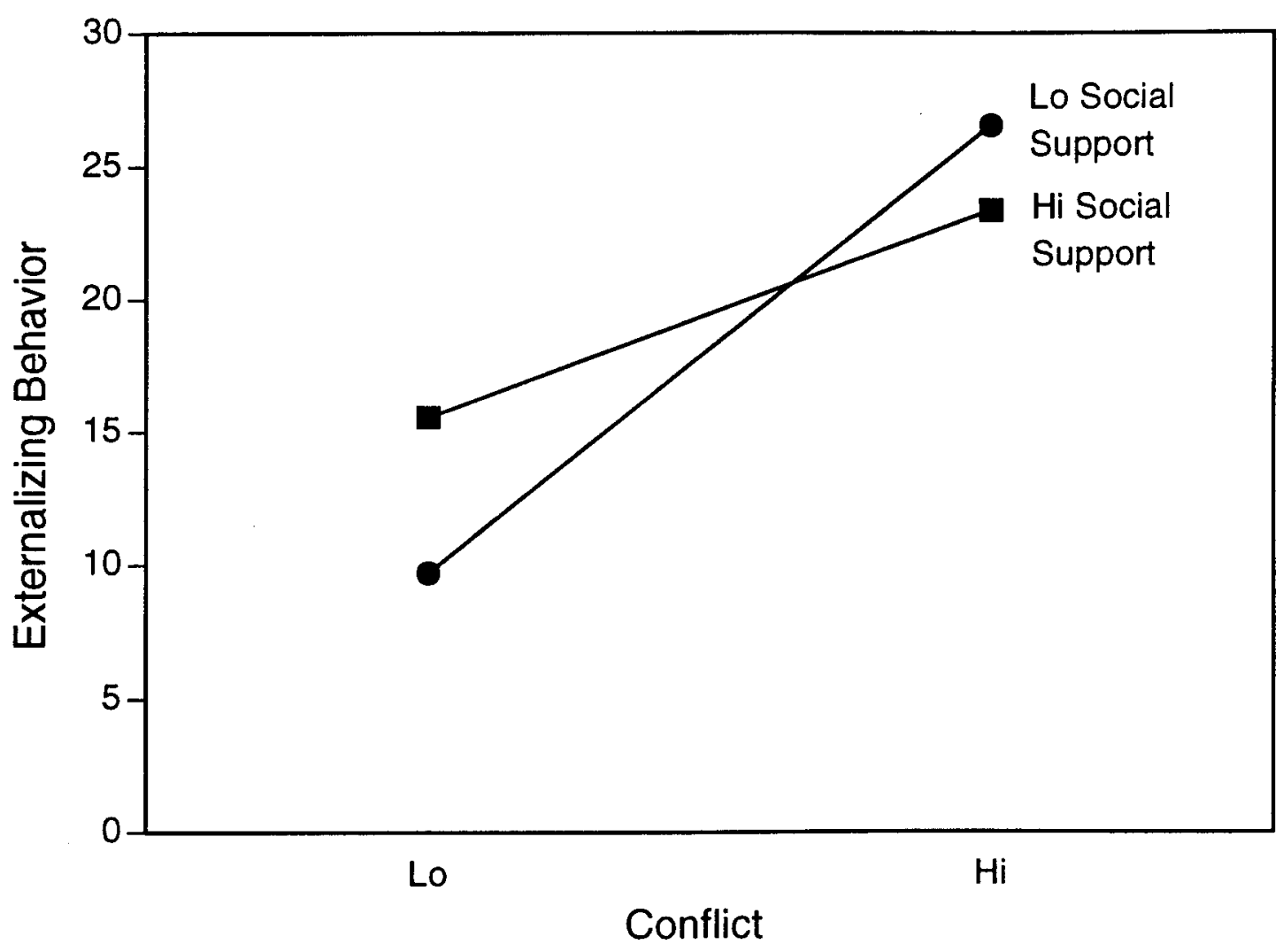


dependent adjustment measures (problem behavior and competence). The parent-reported demographic variables (i.e., income, race, divorce status, respondent's relationship to child and partner (family structure]) were entered first into the equation as covariates in each analysis. Subsequently, each main effect was entered into the equation followed by the interaction term.

The results of the analyses involving the parent-report measures are presented in Tables 6 and 7 . Results revealed a significant main effect of conflict on problem behavior, $\underline{B}$ $=.585, \mathrm{R}^{2}$ change $=.261, \underline{\mathrm{p}}<.001$. Cognitive appraisal had a significant effect on competence, $\underline{B}=-.418, \mathrm{R}^{2}$ change $=$ $.13, \mathrm{p}<.05$, although the conflict $\mathrm{x}$ cognitive appraisal interaction was not significant (contrary to Hypothesis \# 3). There were no significant effects of coping or conflict $\mathrm{X}$ coping interaction effects on the parent-reported dependent variables (contrary to Hypothesis \# 4 and \#5, respectively).

These results indicate that higher levels of conflict as reported by parents were associated with higher levels of parent-reported behavior problems in children (Hypothesis \# 1). Additionally, children who tended to have problematic beliefs about the conflict were seen by their parents as less competent than children endorsing fewer problematic beliefs (Hypothesis \# 2).

Subscale Exploratory Analyses. Subscale analyses were 
Table 6

Summary of Regression Analyses for Parent-Reported Conflict and Dependent Variables--Cognitive Appraisal (Beliefs)

$\begin{array}{lllll} & & & \\ \text { Step } & \text { Variable } & \text { Mult.R } & \mathrm{R}^{2} & \text { change }\end{array}$

Dependent Variable = Competence

\begin{tabular}{lccccc}
\hline 1 & Covariates & .487 & .237 &.-- & .600 \\
2 & Beliefs & .606 & .130 & -.418 & $1.014 *$ \\
3 & Conflict & .612 & .008 & -.113 & .952 \\
4 & B X C & .674 & .079 & 1.601 & 1.202 \\
\hline
\end{tabular}

Dependent Variable = Problem Behavior

\begin{tabular}{cccccc}
\hline 1 & Covariates & .530 & .281 &.--754 \\
2 & Conflict & .736 & .261 & .585 & $2.068 *$ \\
3 & Beliefs & .738 & .003 & -.070 & 1.899 \\
4 & C X B & .738 & $<.001$ & -.130 & 1.731
\end{tabular}

Note.--Covariates = income, race, divorce status, and family structure. "B X C" refers to the Beliefs by Conflict interaction effect.

* $\mathrm{p}<.05$

$\star \star \mathrm{p}<.001$ 
Table 7

Summary of Regression Analyses for Parent-Reported Conflict and Dependent Variables-Coping

\begin{tabular}{lccccc}
\hline Step & Variable & Mult.R & $\mathrm{R}^{2}$ change & Beta & $\mathrm{F}$ \\
\hline \multicolumn{5}{c}{ Dependent Variable $=$ Competence } \\
\hline 1 & Covariates & .487 & .237 &.-- & .6 \\
2 & Conflict & .539 & .054 & -.266 & .717 \\
3 & Coping & .539 & $<.001$ & -.013 & .651 \\
4 & C X C & .55 & .011 & 1.31 & .625 \\
\hline
\end{tabular}

Dependent Variable $=$ Problem Behavior

\begin{tabular}{lccccc}
\hline 1 & Covariates & .53 & .281 &.--- & .754 \\
2 & Conflict & .736 & .261 & .585 & $2.068 *$ * \\
3 & Coping & .74 & .006 & .105 & 1.924 \\
4 & C X C & .74 & $<.001$ & -.178 & 1.751
\end{tabular}

Note.---Covariates = income, race, divorce status, and family structure. "C X C" refers to the Coping by Conflict interaction effect.

$* \underline{p}<.05$ 
computed following the procedures described above. For this set of analyses, the parent-reported conflict variable, the child-reported cognitive appraisal and coping subscales, and the parent-reported dependent measures (problem behavior and competence) were used. The results of the analyses

utilizing the coping subscales revealed a significant effect of self destruction on behavior problems, $\underline{B}=.356, R^{2}$ change $=.073, \underline{p}<.05$. The cognitive appraisal subscale analyses revealed significant effects of self-blame, $\underline{B}=$ $-.469, \mathrm{R}^{2}$ change $=.148, \underline{\mathrm{p}}<.05$, fear of abandonment, $\underline{\mathrm{B}}=$ $-.425, \mathrm{R}^{2}$ change $=.144, \underline{\mathrm{p}}<.05$, and peer concerns, $\underline{\mathrm{B}}=$ $-.554, \mathrm{R}^{2}$ change $=.139, \underline{\mathrm{p}}<.05$, on competence.

A significant conflict $x$ peer concerns interaction effect was found for behavior problems, $\underline{B}=-1.854, \mathrm{R}^{2}$ change $=.087, \underline{\mathrm{p}}<.05$. Follow-up calculations probing this interaction showed that children in high-conflict homes (as reported by parents) who had high peer concerns scores, tended to be seen by their parents as having relatively fewer behavior problems, as compared to those children in high-conflict homes who had lower peer concerns scores. Conversely, those children in low-conflict homes who had high peer concerns scores tended to be seen as having more problematic behavior than their low-conflict, low-peerconcerns counterparts. The conflict $x$ peer concerns interaction effect is depicted in Figure 4. 
Figure 4

Conflict by Peer Concerns Interaction Effect on

Problem Behavior--Parent Report

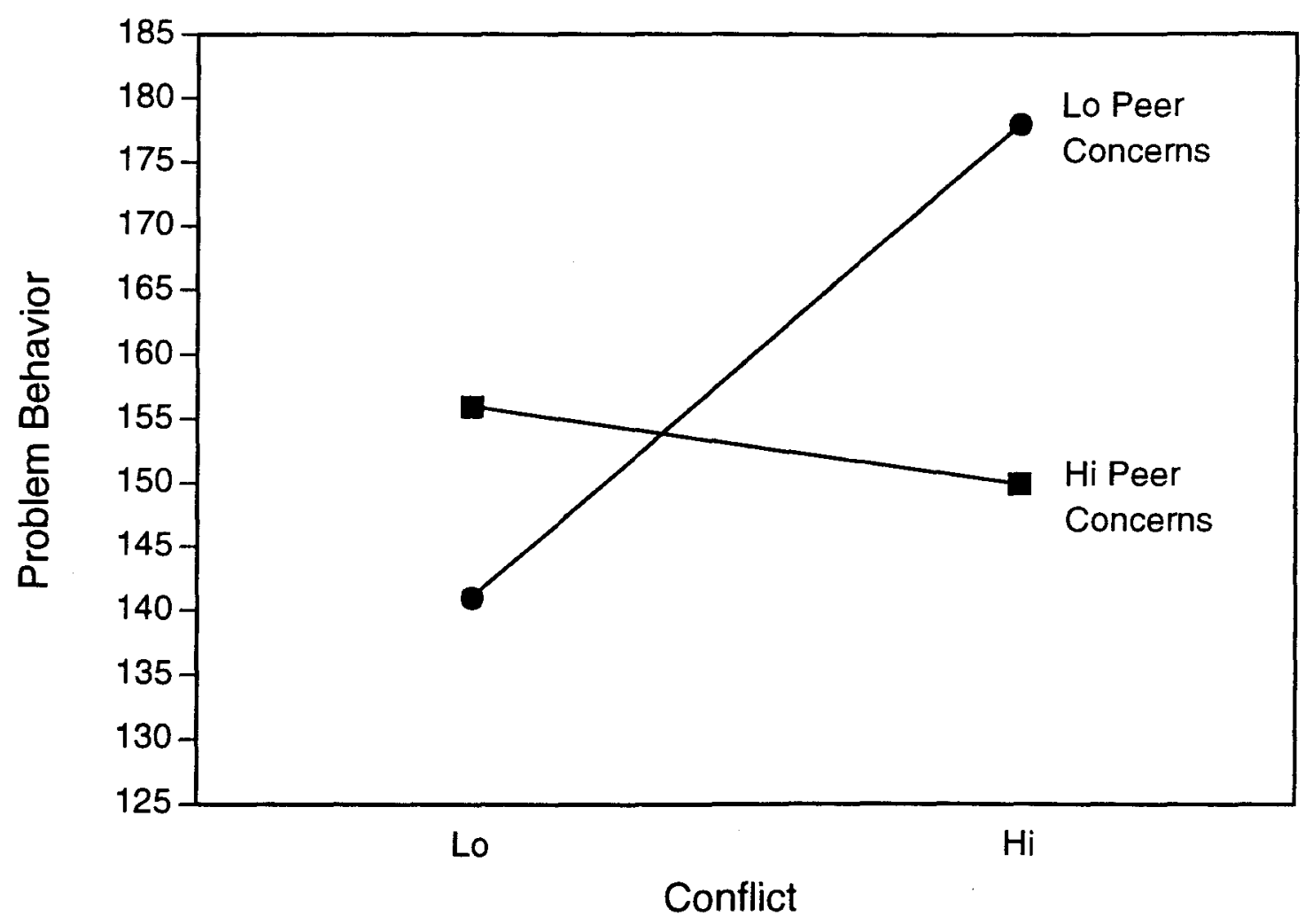


CHAPTER IV

DISCUSSION

The purpose of this study was to examine the potentially moderating effects of children's cognitive appraisal and coping strategies on the deleterious impact of observing interparental aggression on children's psychological well-being. The results of this research highlight the importance of studying children's understanding of their parents' conflicts as well as children's coping responses reported in the face of such conflicts. Although previous findings regarding the harmful effects of conflict on children's adjustment were supported, moderating effects of children's overall cognitive appraisal and coping were not found. The specific coping strategies of social support and avoidance, however, were found to have a moderating effect on children's emotional and behavioral adjustment. Children's statements concerning their peer relationships were also found to moderate the effects of parental conflict on the level of children's problematic behavior as viewed by parents.

In accord with a wealth of research demonstrating the effects of interparental aggression on children's adjustment (Grych \& Fincham, 1990), the present research found that 
more frequent and intense conflicts as perceived by children were associated with higher rates of child-reported externalizing behavior and depression. Higher levels of parent-reported conflict were also associated with problematic child behavior as reported by the parents. These findings support the conclusions of Grych and Fincham that conflict involving more severe forms of aggression is likely to be more upsetting to children and is strongly linked to emotional and behavior problems.

As hypothesized, children's cognitive appraisal was also found to have direct effects on the child-reported adjustment variables (self-worth, externalizing behavior and depression), as well as on parents' views of their child's competence. Thus, children who had more problematic beliefs about their parents' conflicts tended to report a lower sense of self-worth, more symptoms of depression, higher levels of acting out behavior, and were seen by their parents as relatively less socially and academically competent. The results of the cognitive appraisal subscale analyses suggest that many specific types of problematic beliefs are related to children's emotional and behavioral difficulties. Those beliefs impacting children's self-worth included concerns about peer relationships (e.g., "It would upset me if other kids asked a lot of questions about my parents"), fears of abandonment by the parents, worries about the resolution of conflicts, and self-blame. Those 
factors associated with externalizing behavior included fears of abandonment, maternal blame, conflict resolution concerns, and self-blame, and beliefs associated with higher rates of depression included peer concerns, fear of abandonment, resolution concerns, and self-blame.

These findings support the notion that children's thoughts about their parents' conflicts-- their attributions about responsibility and blame and their expectations about what can be done and what will be the outcome of the conflicts-- are important to understanding children's emotional and behavioral functioning (Grych \& Fincham, 1990; Rutter, 1983). Children who develop self-, and parentblaming beliefs and fears about their parents' conflicts were more maladjusted in terms of their self-reported depression and acting-out behavior, as well as in terms of their own sense of self-worth and in their parents' views of their child's competence. Conversely, those notions that tend to be associated with better adjustment include a belief that parental conflict will discontinue in the future, a sense that the child will be cared for by the parents, and the belief that parents' conflicts do not necessarily pertain to the child.

In accord with previous research (Compas, 1987; Grych \& Fincham, 1990; Rutter, 1983), children's cognitive appraisal of their parents' conflicts were found to be moderately associated with children's reported coping strategies. It 
was hypothesized that children's responses to marital conflict are likely to be influenced by their thoughts and beliefs about the conflict. The present research found that children who tend to endorse problematic beliefs (e.g., "MY parents would probably not be fighting if it weren't for me") were more likely to report greater use of ineffective coping responses (e.g., "When my parents have a disagreement or argument, I think about hurting myself"). These findings support Compas' suggestion that children's coping responses to marital conflict are influenced by their beliefs about the conflict.

Children's reported coping strategies were also found to be predictive of children's adjustment. Specifically, those strategies that had a negative effect on children's self-worth included self-destructive acts and a failure to use distraction strategies (e.g., "I go somewhere in order to relax"). Aggressive, self-destructive, and ventilating (e.g., "I yell and scream") responses were related to higher levels of externalizing behavior problems. Aggressive and self-destructive responses were also related to higher levels of depressive symptoms, as was the avoidance strategy (e.g., "I act as though nothing happened"). Consistent with previous research (Compas et al., 1988; Jose et al., 1992; Spivack \& Shure, 1982, 1985), these findings suggest that children's coping patterns used in response to the stress of their parents' conflicts may influence how they view their 
own worth, how dysphoric they feel, and how problematic their general behavior.

Taken together, these findings support Hypothesis \#4 and Hypothesis \# 6, as depicted in Figure 1. That is, the results indicate that the way in which children think about their parents' conflicts predicts the coping responses they develop to deal with this stressor, which in turn, influence the level of their emotional and behavioral adjustment. Hence, the present study provides further support for the connection between children's cognitive appraisal of conflict, children's coping, and general adjustment (Grych \& Fincham, 1990). Children who have less problematic beliefs about their parents' fights appear to utilize more adaptive coping strategies, such as participating in some enjoyable activity or talking to a friend, which may bolster their sense of well-being.

Although it was hypothesized that children's cognitive appraisal and reported coping responses would moderate the effects of the conflict on children's adjustment, this hypothesis was not supported by the findings for children's general beliefs and coping strategies. Because some of the subscales of the cognitive appraisal and coping measures lost internal consistency after being modified for the present research, it is possible that this lowered reliability contributed to the failure to find overall interaction effects. However, the results did reveal 
significant moderating effects of specific coping patterns pertaining to social support (e.g., "I talk to others about how I'm feeling") and avoidance (e.g., "I avoid the problem"). That is, those children exposed to high levels of conflict, but who reported relatively greater use of social supports (to talk to about one's feelings), were found to be relatively lower on externalizing behavior than those children in high-conflict homes who reported less usage of the social support coping strategy. Interestingly, children in low-conflict homes reporting greater use of social supports had higher levels of externalizing behaviors (as compared to the low-conflict, low-social-support group). It may be that for children in homes characterized by lower levels of interparental conflict, such contacts could lead to social acting out that is manifested at a low level. For children in highly conflictual homes, however, the use of social support strategies appear to moderate the level of externalizing behavior.

With regard to the avoidance coping results, it was found that children in high-conflict homes who reported greater use of avoidance responses tended to be less depressed and reported less externalizing behavior than those children in high-conflict homes that endorsed fewer avoidance strategies (although the high-conflict group was higher overall on externalizing and depression than the lowconflict group). Although coping strategies in the 
avoidance subscale were considered "ineffective" strategies, it appears that for children in highly conflictual.homes, these responses moderate depression and externalizing despite that fact that such strategies were found to be associated with greater depression and externalizing for the overall sample, and for children in low-conflict homes, in particular. A potential explanation is that acting as though nothing has happened and going off by oneself could conceivably assist the child in a high-conflict home in separating oneself from the emotional arousal of the fighting (Cummings et al., 1989), which may be ameliorative for this sub-population. This finding is consistent with previous research showing that adolescents who are in highly conflictual homes but are more emotionally autonomous tend to be better adjusted than less autonomous adolescents (Fuhrman \& Holmbeck, 1993).

Children's notions about peer relationships were also found to moderate the level of parent-reported problematic child behavior. Children who endorsed statements such as "I'd rather be alone than play with other kids," or responded negatively to statements such as "I like talking to my friends as much now as I used to," were seen by their parents as having fewer behavior problems for those families in high-conflict homes. However, children in high-conflict homes who indicated greater peer interest or support le.g., "I like playing with my friends as much now as I used to" or 
"My friends understand how I feel about my parents") were reported to have greater behavioral problems. These

findings are in contrast to the results discussed above that children's use of social supports to discuss their feelings predict less externalizing behavior as reported by children. Because it is unknown whether such supports involve peers, family members, or other adults, the explanation for these apparently conflicting findings is unclear. It is possible that in highly conflictual homes, children's peer involvements become a source of parent-child conflict or that peer activities for this group are related to behavior patterns that are troublesome to parents, but not to children.

To summarize, the results of this study suggest that high levels of interparental aggression have a potent impact on children's psychological functioning. How children think about and cope with interparental conflict appear to affect the level of children's adjustment, and particular coping strategies and beliefs were found to moderate the deleterious effects on adjustment. Children's use of social supports and avoidance strategies appear to benefit children's emotional and behavioral adjustment in highly conflictual homes, but such responses do not necessarily improve upon children's adjustment in low-conflict homes. Nonetheless, the results of this study were found to be consistent with previous research (Garmezy, Masten, 
Nordstrom \& Ferrarese, 1979; Rutter, 1979) on protective factors in high-risk children, which has shown that children who develop a positive relationship with a caring adult are less likely to develop severe emotional disturbance though faced with adverse environmental conditions. Like these studies, the present research suggests that the use of social supports can act as a "protective" factor in buffering the effects of high levels of interparental aggression.

The findings in this study underscore the importance of utilizing both children and their parents as sources of information in this literature. The child-reported measures provided a wealth of information about children's perceptions of their parents' conflicts, about children's beliefs about the conflict and their coping responses, as well as children's estimations of their own emotional and behavioral functioning. By including both parent and child reports, the results provided corroborating support for the deleterious effects of conflict on adjustment and evidence for the role of children's cognitive appraisal and coping that would not have been obtained by using only parent or child reports. As found in previous research (Kurdek \& Berg, 1987; Wierson et al., 1988), the analyses of the child-report data resulted in significant effects not found for the parent-report data. This trend may reflect, as suggested by Kurdek and Berg, the greater relevance 
sometimes provided by children's report when attempting to assess children's own psychological functioning.

An alternative explanation for the scarcity of significant findings in the parent-report data may be the small sample size of parent respondents, which may have resulted in low power. Thus, the results of this study may not wholly reflect the potential interaction effects when examining the parent conflict and parent outcome variables. Additionally, the present study relied on parent-report for family income and family structure information. Because many of the children's parents failed to return the questionnaire, these particular demographic variables are unknown for part of the child sample and the level of control over extraneous variance due to family structure may have been compromised.

It should be noted that the present research did not provide exclusionary criteria on the basis of family structure. Although previous research (Bishop \& Ingersoll, 1989; Long, 1986) has shown that level of conflict is a better predictor of child adjustment than family structure, it may have been useful to limit inclusion to families of natural parents in the home or natural and step-parents in the home in order to achieve a more homogeneous sample. This restriction would also have helped ensure that responses to questions actually pertained to interparental dyads. Although the present sample allows for broad 
generalization to many types of family constellations, potential error variance may have been heightened by the procedures used.

Other limitations of the present research include potential sampling bias, lack of control over possible effects of parent-child aggression, and use of a nonlongitudinal design. Because only a portion of students from each school participated in the study (average $12 \%$ ) on a volunteer basis, and less than half of the subjects' parents completed the measures $(40 \%)$, the present sample of subjects who chose to participate is not necessarily representative of the larger population of middle-school children and their parents. Further, as seen in the summary statistics presented above, this urban sample appears to be slightly more conflictual and more poorly adjusted than has been found in previous research (e.g., Straus, 1990), which limits the generalizability of the present findings.

This research did not control for possible additional effects of parent-child aggression, which has been found to be related to adjustment problems in children (Hughes, 1988). Although it is possible that some of the variance in children's outcome scores may be attributable to the effects of parent-child aggression, the purpose of the present research was to study the general model of the moderating effects of cognitive appraisal and coping in the interparental aggression-child adjustment relationship, and 
not to determine whether interparental aggression affected child adjustment, per se. Nonetheless, it is possible that greater control over extraneous parent-child aggression variance would result in a more precise analysis of the model.

Because the present hypotheses were not examined through the use of a longitudinal design, the implications drawn from these findings should be considered with caution. Longitudinal research is needed to verify the impact of interparental aggression and to fully assess the role of cognitive appraisal and coping. More research should be conducted in order to address the limitations of the present research design.

In conclusion, this study has made important contributions to the understanding of the effects of interparental aggression on children's adjustment by examining children's cognitive appraisal and coping strategies considered in reference to their parents' conflicts. The findings support previous research on the deleterious impact of high levels of interparental aggression, and show how children's coping strategies and beliefs about the conflict are highly predictive of children's level of psychological well-being. Further, children's use of social support and avoidance strategies were found to be potentially important protective factors for children in highly conflictual homes, while peer 
avoidance or withdrawal was found to predict fewer behavior problems as viewed by parents in such homes.

These findings may have implications for the implementation of secondary prevention and treatment programs, suggesting that such interventions may be useful for this population. As reported in previous research (Dubow, Schmidt, MCBride, Edwards, \& Merk, 1993), children appear to be able to effectively utilize techniques that broaden their coping repertoire for dealing with stressful experiences. Children exposed to high levels of interparental aggression may be able to benefit from such approaches that incorporate seeking out beneficial social contacts or that foster appropriate levels of emotional autonomy. Further research is needed to ascertain whether interventions focusing on building effective coping responses and addressing problematic beliefs are helpful for children in homes characterized by high levels of interparental aggression. 
APPENDIX A

PARENT PERMISSION FORM AND LETTER 
Dear Parent:

I am a doctoral student at Loyola University and, with the cooperation of $\mathrm{xxxx}$ and other local area schools, I have been given permission to conduct a research project with $6 \mathrm{th}, 7 \mathrm{th}$, and $8 \mathrm{th}$ graders and their families. I am writing to invite you and your child to participate in this project.

The purpose of this study is to determine some of the ways in which children understand and respond to family patterns. Your participation will help us learn more about children's development and family living so that we may provide better services for children and families in the future.

You and your child will each be asked to fill out a questionnaire that takes only about 40 minutes to complete. We are NOT interested in any one person's answers but how people in a large number of schools respond in general. All materials are entirely confidential. Numbers are used so that NO NAMES are attached to any of the questionnaires and all answers are held in strict confidence. Participation is completely voluntary and you or your child may withdraw from the study at any time. Your questionnaire would be mailed to you with a stamped return envelope and your child would be given a questionnaire at school.

On the attached form, please indicate whether or not you wish to be included in this project and have your child return the form to school. If you have any questions, please call

Mary Jo Rogers at 312-363-6700, ext. 537. You may leave a message if I am not available and I will return your call.

Thank you for your cooperation!

Sincerely,

Mary Jo Rogers, M.A. 
PLEASE RETURN THIS FORM TO XXXX SCHOOL BY NOV. 23

YES, we agree to participate in the Loyola study described above and we understand we may withdraw

from the study at any time for any reason (name and information given below).

NO, we do not wish to participate

Child's Name

$\overline{\text { Parent or Guardian Signature }}$

Address :

Phone:
Date

Child's Signature

Grade :

Room Number: 
APPENDIX B

CHILD QUESTIONNAIRE 


\section{ID \#}

Hi. In this packet are some questions that have to do with kids and their families. Some questions are about how you feel and what you do, and some questions are about what parents, or what the adults that live in your house do. Your answers are strictly confidential, so no one else will see them. Also, we will not be looking at your answers by themselves; we are just interested in what kids your age think and feel about different things.

These questions will not be included with your packet:

Your name:

Your address: zip code:

Your phone number:

Your birthdate:

Your age:

Are you a boy or girl?

Your school:

Your grade in school:

Your favorite T.V. show:

Your favorite hobby:

Today's date:

Your ethnic group:

African-American

Asian-American

Hispanic 
All families have trouble getting along sometimes. No matter how well parents get along, there are times when they disagree or just have fights because they're in a bad mood or tired or for some other reason. Parents use many different ways of trying to deal with their disagreements. These are some things that your parents might do when they have an argument. Please circle how many times in the past year that your parents, or the adults that live in your house, did these things when they had a disagreement.

When my parents had a disagreement or argument, they:

1. Talked about it.

0 times $1-2$ times $3-10$ times $11-20$ times more than 20 don't know

2. Said some things to help explain their side.

0 times $1-2$ times 3-10 times $11-20$ times more than 20 don't know

3. Had someone come in to help settle things. 0 times $1-2$ times $3-10$ times $11-20$ times more than 20 don't know

4. Stomped out of the room or the house.
0 times
1-2 times
3-10 times
11-20 times
more than 20 don't know

5. Insulted or swore at the other.

0 times $1-2$ times $3-10$ times $11-20$ times more than 20 don't know

6. Said they would hit or hurt the other.

0 times $1-2$ times $3-10$ times $11-20$ times more than 20 don't know 
7. Said something to hurt the other's feelings. 0 times 1-2 times 3-10 times $11-20$ times more than 20 don't know

8. Threw something at the other.

0 times 1-2 times 3-10 times $11-20$ times more than 20 don't know

9. Pushed or shoved the other.

0 times 1-2 times 3-10 times $11-20$ times more than 20 don't know

10. Slapped the other.

0 times $1-2$ times $3-10$ times $11-20$ times more than 20 don't know

11. Kicked or hit the other with a fist.

0 times $1-2$ times $3-10$ times $11-20$ times more than 20 don't know

12. Beat the other up.

0 times $1-2$ times $3-10$ times $11-20$ times more than 20 don't know

13. Hit or tried to hit the other with something.

0 times $1-2$ times $3-10$ times $11-20$ times more than 20 don't know 
Every once in a while parents get into arguments. Below are some statements about kids, parents, and when parents fight. Some of these statements are true about how you think and feel about your parents and their fights, while some of them are not true for how you think or feel.

For those that are true for you, circle YES. For those that are not true for you, circle No. There are no right or wrong answers. Your answers will just tell us some things you are thinking and feeling.

1. It would upset me if other kids asked a lot of questions about my parents......................... nes no

2. It was usually my father's fault when my parents had a

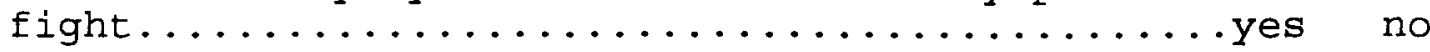

3. I sometimes worry that both my parents will want to live without me.....................

no

4. When my family was unhappy it was usually because of my mother........................

no

5. My parents will always fight...............

6. My parents often argue with each other after I

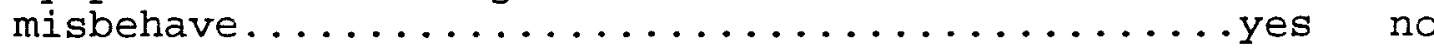

7. I like talking to my friends as much now as I used

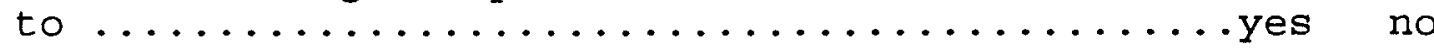

8. My father is usually a nice person............. yes no

9. It's possible that both my parents will never want to see me again.......................... nes no

10. My mother is usually a nice person.............. nes no

11. If I behave better I might be able to stop my parents from fighting........................ nes no

12. My parents would probably be happier if I were never born.......................... no

13. I like playing with my friends as much now as I used

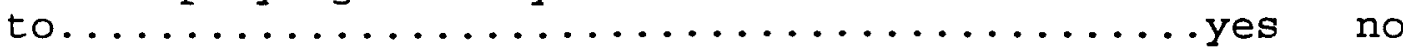

14. When my family was unhappy it was usually because of something my father said.................. nes no

15. I sometimes worry that I'll be left all alone...yes no 
16. Often I have a bad time when I'm with my

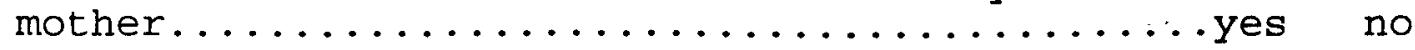

17. My family will probably stop fighting.........yes no

18. My parents probably argue more when I'm with them than

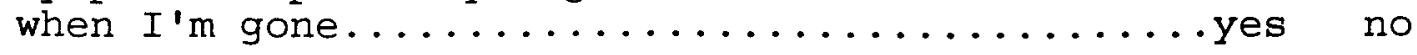

19. I'd rather be alone than play with other kids...yes no

20. My father caused most of the trouble in my

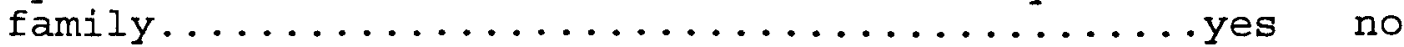

21. I feel that my parents still love me..........yes no

22. My mother caused most of the trouble in my

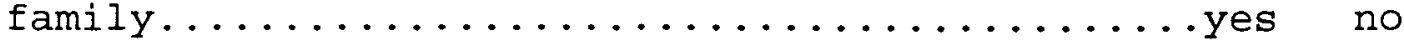

23. My parents will probably see that they have made

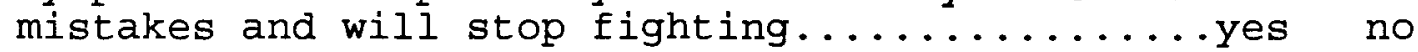

24. My parents are happier when I'm with them than when

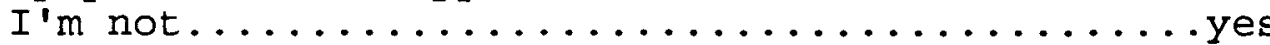

25. My friends and I do many things together.......yes no

26. There are a lot of things about my father I

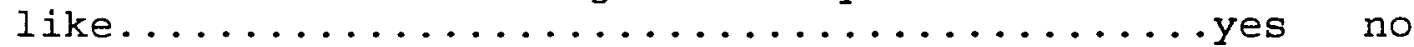

27. I sometimes think that one day I may have to go live

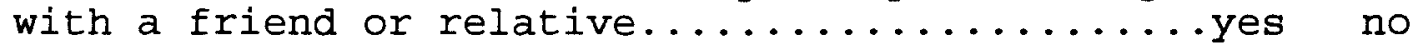

28. My mother is more good than bad.................. nes

29. I sometimes think that my parents will one day stop

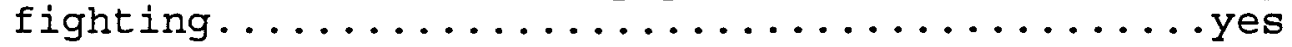

no

30. I can make my parents unhappy with each other by what

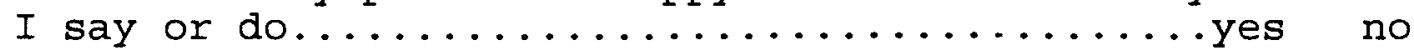

31. My friends understand how I feel about my

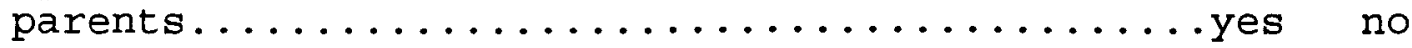

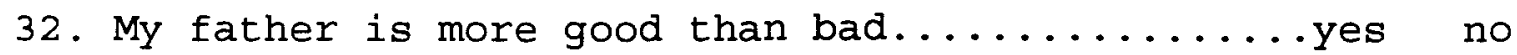

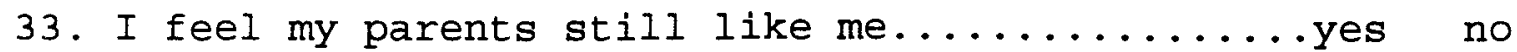

34. There are a lot of things about my mother I

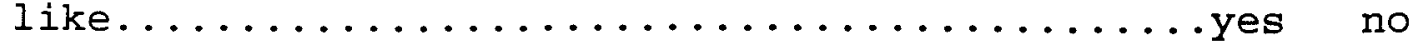


35. I sometimes think that once my parents realize how much I want them to, they'll stop fighting..........yes no

36. My parents would probably not be fighting if it weren't for me......................... nes no 
Kids do a lot of different things when their parents have disagreements or arguments. Below is a list of things that kids do when their parents argue. Please mark how often you do each of these things when your parents argue.

There are no right or wrong answers, just mark what you really do.

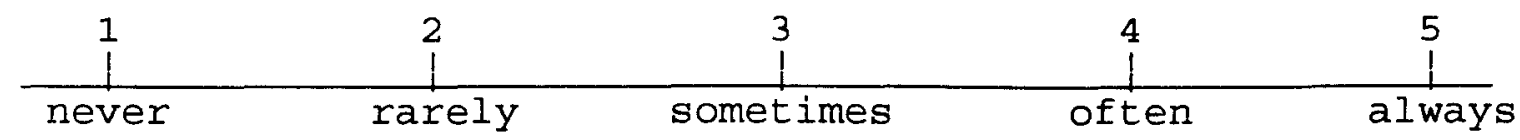

When my parents have a disagreement or argument,

1. I cry.

2. I do something that I enjoy.

3. I get into fights or argue with people.

- 4. I smoke cigarettes.

5. I talk to others about how I'm feeling.

6. I try to change something about the situation to make it better.

7. I avoid the problem.

8. I change myself to make things better.

9. I release, or let out, my feelings.

10. I exercise or play a sport.

11. I take out my frustration on someone or something else.

12. I think about hurting myself.

13. I succeed at telling others how I feel.

14. I try to convince somebody to act differently.

15. I keep my feelings and thoughts to myself.

16. I change my actions to be a better person. 


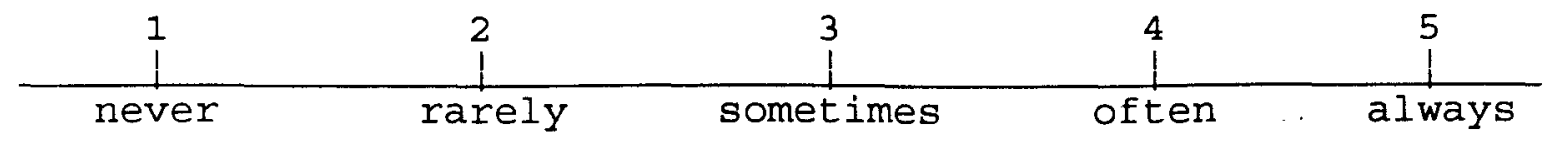

17. I just let my feelings out.

18. I go somewhere in order to relax.

19. I throw things or break things.

20. I take drugs or drink alcohol.

21. I find a close friend or family member to talk to about my problem.

22. I act to correct the problem in somebody or some thing else.

23. I act as though nothing has happened.

24. I change something about myself to solve the problem.

25. I yell and scream.

26. I take a nap or go to sleep.

27. I hurt somebody who didn't have anything to do with the problem.

28. I do something dangerous or risky.

29. I show people I'm close to how I'm feeling.

30. I solve the problem by getting someone else to change.

31. I go off by myself.

32. I try to act differently myself in order to solve the problem. 
We have some sentences here that describe what kids are like. Kids are different from one another and we are interested in what you are like.

First, decide which kind of kid you are most like, the sentence on the left or the sentence on the right.

Next, after you decide what kind of kid you are most like, decide whether that is sort of true for you, or really true for you, and check that line.

For each question, mark only one line. Sometimes you will mark on one side of the page, and sometimes you will mark on the other side of the page, but only mark one line per question.

\section{Sample Sentence}

a.

Some kids would

rather play out-

doors in their

spare time
BUT

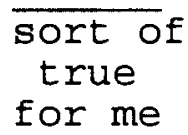

Other kids would rather watch T.V.

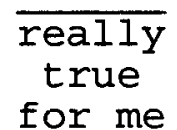

for me sort of

true

for me

1 .

Some kids are

often unhappy

with themselves
Other kids

BUT

pleased with

themselves.

$\begin{array}{cc}\text { really } & \text { sort of } \\ \text { true } & \text { true } \\ \text { for me } & \text { for me }\end{array}$

$\begin{array}{ll}\text { real1y } & \text { sort of } \\ \text { true } & \text { true } \\ \text { for me for me }\end{array}$ 
2 .

Some kids don't

like the way

BUT

Other kids do

they are leading

like the way

their life

are leading

their life.

$\begin{array}{cc}\text { really } & \text { sort of } \\ \text { true } & \text { true } \\ \text { for me } & \text { for me }\end{array}$

$\overline{\text { really }}$

true

for me

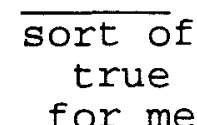

3 .

Some kids are happy with themselves as

BUT a person

Other kids are often not happy with themselves as a person.

$\begin{array}{cc}\overline{\text { really }} & \text { sort of } \\ \text { true } & \text { true } \\ \text { for me } & \text { for me }\end{array}$

BUT

Some kids like the kind of person they are
Other kids often wish they were someone else.

$\begin{array}{cc}\overline{\text { really }} & \overline{\text { sort of }} \\ \text { true } & \text { true } \\ \text { for me } & \text { for me }\end{array}$

really
true
for me

really

true

for me
$\overline{\text { sort of }}$ true
for me

\section{5 .}

Some kids are very happy being the way they are
BUT

$$
\begin{aligned}
& \text { sort of } \\
& \text { true } \\
& \text { for me }
\end{aligned}
$$

Other kids wish wish they were different. $\overline{\text { sort of }}$ true

for me

$\begin{array}{cc}\text { really } & \text { sort of } \\ \text { true } & \text { true } \\ \text { for me } & \text { for me }\end{array}$

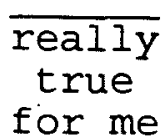

$\overline{\text { sort of }}$ true

for me 
6.

Some kids are not very happy with the way they do a lot of things

really true for me sort of true for me
BUT

Other kids think the way they do things is fine.

$\begin{array}{cc}\overline{\text { really }} & \overline{\text { sort of }} \\ \text { true } & \text { true } \\ \text { for me } & \text { for me }\end{array}$


Below is a list of things that describe kids. For each sentence that describes you now or within the past 6 months, please circle the 2 if the sentence is very true or often true of you. Circle the 1 if the sentence is somewhat or sometimes true of you. If the sentence is not true of you, circle the 0 .

$0=$ Not True

1 = Somewhat or Sometimes True

2 = Very True or Often True

012 1. I argue a lot

$\begin{array}{llll}0 & 1 & 2 & 2\end{array}$

$\begin{array}{llll}0 & 1 & 2 & 3\end{array}$. I have trouble concentrating or paying attention

0124 . I am mean to others

012 5. I try to get a lot of attention

$\begin{array}{llll}0 & 1 & 2 & 6\end{array}$. I destroy my things

$\begin{array}{lll}0 & 1 & 2\end{array}$. I destroy things belonging to others

0128 . I disobey my parents

$\begin{array}{llll}0 & 1 & 2 & 9\end{array}$. I disobey at school

012 10. I don't feel guilty after doing something I shouldn't

012 11. I feel that others are out to get me

012 12. I get in many fights

012 13. I hang around with kids who get in trouble

012 14. I act without stopping to think

012 15. I lie or cheat

012 16. I physically attack people

012 17. My school work is poor 
012 18. I would rather be with older kids than with kids my own age

012 19. I run away from home

01220 . I scream a lot

012 21. I am secretive or keep things to myself

01222 . I set fires

012 23. I show off or clown

$\begin{array}{lll}0 & 2 & 24\end{array}$. I steal things at home

012 25. I steal things from places other than home

012 26. I am stubborn

012 27. My moods or feelings change suddenly

01228 . I am suspicious

012 29. I swear or use dirty language

012 30. I talk too much

012 31. I tease others a lot

012 32. I have a hot temper

012 33. I think about sex too much

01234 . I threaten to hurt people

012 35. I cut classes or skip school

012 36. I am louder than other kids

012 37. I use alcohol or drugs other than for medical conditions 
Kids sometimes have different feelings and ideas.

This form lists the feelings and ideas in groups. From each group, pick one sentence that describes you best for the PAST TWO WEEKS. After you pick a sentence from the first group, go on to the next group.

There is no right answer or wrong answer. Just pick the sentence that best describes the way you have been recently. Put a mark like this $x$ next to your answer. Put the mark on the line next to the sentence that you pick.

Here is an example how this form works. Try it. Put a mark next to the sentence that describes you best.

Example:

I read books all the time.

I read books once in a while.

I never read books.

1. I am sad once in a while I am sad many times I am sad all the time

2. Nothing will ever work out for me I am not sure if things will work out for me _ Things will work out for me okay

3 . I do most things okay I do many things wrong I do everything wrong

4 . I have fun in many things I have fun in some things Nothing is fun at all

5 . I am bad all the time I am bad many times I am bad once in a while 
6 . I think about bad things happening to me once in a while I worry that bad things will happen to me I am sure that terrible things will happen to me

7. I hate myself

I do not like myself I like myself

8 .

All bad things are my fault Many bad things are my fault Bad things are not usually my fault

9. I do not think about killing myself I think about killing myself but $I$ would not do it I want to kill myself

10. I feel like crying every day I feel like crying many days I feel like crying once in a while

11. Things bother me all the time Things bother me many times Things bother me once in a while

12 . I like being with people I do not like being with people many times I do not want to be with people at all

13. I cannot make up my mind about things It is hard to make up my mind about things I make up my mind about things easily

14. I look okay There are some bad things about my looks I look ugly

15. I have to push myself all the time to do my schoolwork I have to push myself many times to do my schoolwork Doing schoolwork is not a big problem 
16. I have trouble sleeping every night I have trouble sleeping many nights I sleep pretty well

17. I am tired once in a while I am tired many days I am tired all the time

18. Most days I do not feel like eating Many days I do not feel like eating I eat pretty well

19. I do not worry about aches and pains I worry about aches and pains many times I worry about aches and pains all the time

20 . I do not feel alone I feel alone many times I feel alone all the time

21. I never have fun at school I have fun at school only once in a while I have fun at school many times

22 . I have plenty of friends I have some friends but I wish I had more I do not have any friends

23. My school work is all right

My school work is not as good as before

_ I do very badly in subjects I used to be good in

24. I can never be as good as other kids I can be as good as other kids if I want to I am just as good as other kids

25 . Nobody really loves me

I am not sure if anybody loves me
I am sure that somebody loves me 
26. I I usually do what I am told

- I do not do what I am told most times

- I never do what I am told

27.

I get along with people

I get into fights many times

- I get into fights all the time 
APPENDIX C

PARENT QUESTIONNAIRE 
Dear Parent:

Thank you for participating in this important study! We are now completing the last stage of the project: Parent Questionnaires. Enclosed you will find your research questionnaire and a stamped return envelope. Please complete and return the questionnaire in the next 7 days or as soon as possible.

I want to remind you that NO NAMES will be attached to any of the responses and all information is entirely confidential. We are not looking at any one person's answers, but only the general answers of very large group of people in many different schools.

The first part of the questionnaire gathers basic information, the second part asks about couple's problemsolving, and the last part asks you questions about your child's behavior. Because this packet is used with a large number of people, some questions will seem like they don't apply to you, but please try to answer as best and as openly as you can.

When the project is completed, a summary of the results of the study will be made available at your child's school. If you would like a copy of the results sent to you, please enclose a self-addressed, stamped envelope with your questionnaire.

The information from this research project will help us be of better assistance to children and families in the future. Your participation is greatly appreciated. If you have any questions, please call me at (312) 363-6700, extension 537 .

Sincerely,

Mary Jo Rogers, M.A.

Loyola University Chicago 
INFORMATION FORM

ID \#

Instructions: Questions regarding "your child" refer to your $6 \mathrm{th}, 7 \mathrm{th}$, or $8 \mathrm{th}$ grader who also participated in this study. If more than one child participated, then consider only the older child in this questionnaire.

Questions regarding "your partner" refer to your significant other living in the home: either the parent of this child, the child's step-parent, or your significant other. If you are not living with your partner, then include the parent of this child living outside the home or a former spouse or significant other living outside the home.

Today's date:

Your child's birthdate:

Your child's age:

Grade in school:

If your child is in a special classroom, what type is it?

If you work outside the home, what do you do and what is your pay per year?

If your partner works outside the home, what does your partner do and how much is his/her pay per year?

Overall, about how much money comes into your home each year?
1. $0-\$ 5,000$
2. $6,000-10,000$
3. $11,000-20,000$
4. $21,000-30,000$ $31,000-40,000$
6.
7. $41,000-50,000$
5 .
8 .
9 . $51,000-60,000$
10 . $61,000-70,000$ $71,000-80,000$ over 80,000

What is your relationship to the child in this study? biological mother step-mother adoptive mother/father biological father step-father other:

How is your partner related to the child biological mother step-mother adoptive mother/father in this study? biological father step-father other: 
ID \#

What is your relationship to your partner in this study? my husband/wife living with us my former spouse NOT living with us (for how long? significant other living with us not living with us other: no "partner"

Are you divorced? yes no

What is your child's racial background? Asian Black Indian Hispanic Native American White Other: 
No matter how well a couple gets along, there are times when they disagree, get annoyeed with the other person or just have spats or fights because they're in a bad mood or tired or for some other reason. They also use many different ways of trying to settle their differences. Listed below are some different things that you and your partner might do when you have an argument. Circle how many times in the past 12 months each of these occurred.

a. Discussed an issue calmly

\begin{tabular}{|c|c|c|c|c|c|c|}
\hline \multirow{3}{*}{$\begin{array}{l}\text { once } \\
\text { never }\end{array}$} & \multirow{2}{*}{ twice } & \multirow[b]{2}{*}{$3-5$} & \multicolumn{4}{|c|}{ more } \\
\hline & & & $6-10$ & $11-20$ & than & don't \\
\hline & & times & times & times & 20 & know \\
\hline
\end{tabular}

b. Got information to back up your/his/her side of things

\begin{tabular}{lrrrrr}
\hline $\begin{array}{l}\text { once } \\
\text { never }\end{array}$ & twice & $3-5$ & $6-10$ & $11-20$ & $\begin{array}{c}\text { more } \\
\text { than }\end{array}$ \\
& times times & times & 20 & know \\
\hline
\end{tabular}

c. Brought in or tried to bring in someone to help settle things

\begin{tabular}{lrrrrl}
\hline $\begin{array}{l}\text { once } \\
\text { never }\end{array}$ & twice & $3-5$ & $6-10$ & $11-20$ & $\begin{array}{c}\text { more } \\
\text { than }\end{array}$ \\
& times times & times & 20 & know \\
\hline
\end{tabular}

d. Insulted him/her/you or swore at him/her/you

\begin{tabular}{|c|c|c|c|c|c|c|}
\hline $\begin{array}{l}\text { once } \\
\text { never }\end{array}$ & twice & $3-5$ & $6-10$ & $11-20$ & $\begin{array}{l}\text { more } \\
\text { than }\end{array}$ & don't \\
\hline & & times & times & times & 20 & know \\
\hline
\end{tabular}


e. Sulked or refused to talk about an issue

\begin{tabular}{lccccc}
\hline once & twice & $3-5$ & $6-10$ & $11-20$ & $\begin{array}{c}\text { more } \\
\text { than }\end{array}$ don't \\
& times times & times & 20 & know \\
\hline
\end{tabular}

f. Stomped out of the room or house or yard

\begin{tabular}{|c|c|c|c|c|c|c|}
\hline \multirow{2}{*}{$\begin{array}{l}\text { once } \\
\text { never }\end{array}$} & \multirow[t]{2}{*}{ twice } & $3-5$ & \\
\hline & & times & times & times & 20 & know \\
\hline
\end{tabular}

g. Cried

\begin{tabular}{lrrrrr}
\hline once & twice & $3-5$ & $6-10$ & $11-20$ & more \\
never & than & don't \\
& & times & times & 20 & know \\
\hline
\end{tabular}

h. Did or said something to spite him/her/you

\begin{tabular}{lccccc}
\hline once & twice & $3-5$ & $6-10$ & $11-20$ & $\begin{array}{c}\text { more } \\
\text { never }\end{array}$ \\
& times & times & times & 20 & know \\
\hline
\end{tabular}

i. Threatened to hit $\mathrm{him} / \mathrm{her} / \mathrm{you}$ or to throw something at him/her/you

\begin{tabular}{lccccc}
\hline once & twice & $3-5$ & $6-10$ & $11-20$ & $\begin{array}{c}\text { more } \\
\text { than }\end{array}$ \\
& times don't & times & times & 20 & know \\
\hline
\end{tabular}

j. Threw or smashed or hit or kicked something

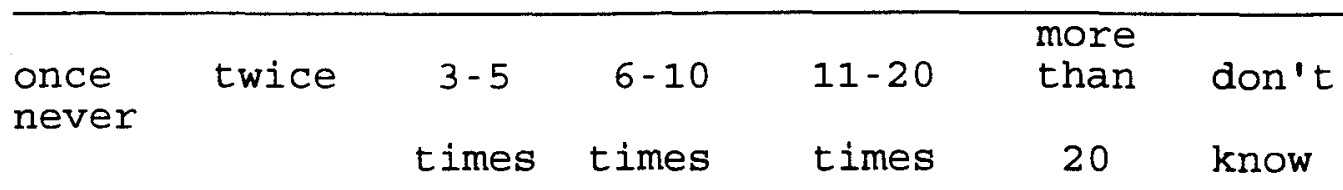


k. Threw something at him/her/you

\begin{tabular}{lrrrrr}
\hline once & twice & $3-5$ & $6-10$ & $11-20$ & $\begin{array}{c}\text { more } \\
\text { than }\end{array}$ don't \\
& times times & times & 20 & know \\
\hline
\end{tabular}

1. Pushed, grabbed, or shoved him/her/you

\begin{tabular}{|c|c|c|c|c|c|c|}
\hline \multirow{3}{*}{$\begin{array}{l}\text { once } \\
\text { never }\end{array}$} & \multirow[b]{2}{*}{ twice } & \multirow[b]{2}{*}{$3-5$} & \multirow[b]{2}{*}{$6-10$} & \multicolumn{3}{|c|}{ more } \\
\hline & & & & $11-20$ & than & don't \\
\hline & & times & times & times & 20 & know \\
\hline
\end{tabular}

m. Slapped him/her/you

\begin{tabular}{lccccc}
\hline $\begin{array}{l}\text { once } \\
\text { never }\end{array}$ & twice & $3-5$ & $6-10$ & $11-20$ & $\begin{array}{c}\text { more } \\
\text { than }\end{array}$ don't \\
& times times & times & 20 & know \\
\hline
\end{tabular}

n. Kicked, bit ot hit him/her/you

\begin{tabular}{lccccc}
\hline $\begin{array}{l}\text { once } \\
\text { never }\end{array}$ & twice & $3-5$ & $6-10$ & $11-20$ & $\begin{array}{c}\text { more } \\
\text { than }\end{array}$ \\
& times don't \\
& & times & times & 20 & know \\
\hline
\end{tabular}

o. Hit or tried to hit him/her/you

\begin{tabular}{lccccc}
\hline once & twice & $3-5$ & $6-10$ & $11-20$ & $\begin{array}{c}\text { more } \\
\text { than }\end{array}$ \\
& times don't & times & times & 20 & know \\
\hline
\end{tabular}


p. Beat him/her/you up

\begin{tabular}{lccccc}
\hline once & twice & $3-5$ & $6-10$ & $11-20$ & $\begin{array}{c}\text { more } \\
\text { than }\end{array}$ don't \\
& & times times & times & 20 & know \\
\hline
\end{tabular}

q. Choked him/her/you

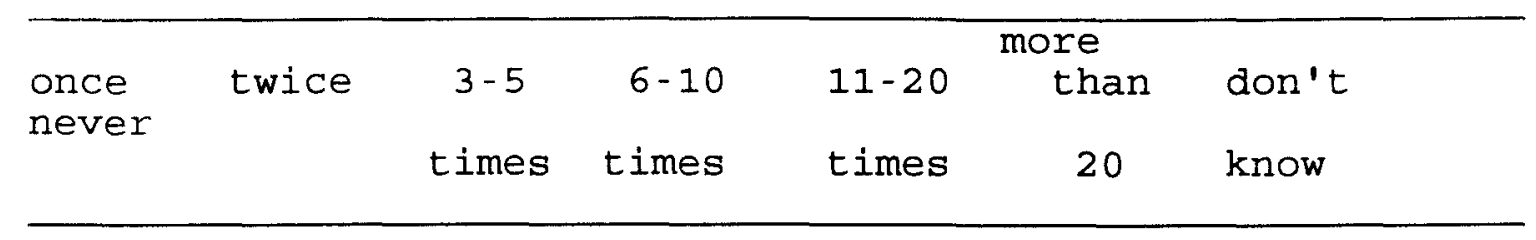

r. Threatened him/her/you with a knife or gun

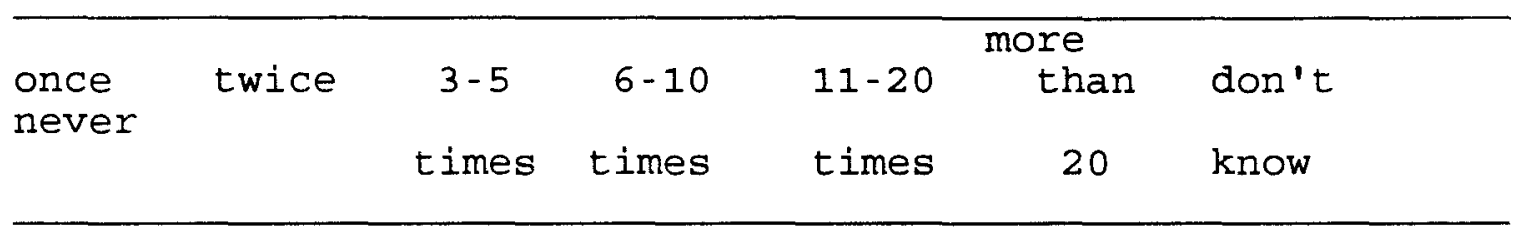

s. Used a knife or fired a gun

\begin{tabular}{lrrrcl}
\hline $\begin{array}{l}\text { once } \\
\text { never }\end{array}$ & twice & $3-5$ & $6-10$ & $11-20$ & $\begin{array}{c}\text { more } \\
\text { than }\end{array}$ \\
& times don't & times & times & 20 & know \\
\hline
\end{tabular}


Below is a list of items that describe children. For each item that describes your child now or within the past 6 months, please circle the 2 of the item is very true or often true of your child. Circle the 1 if the item is somewhat or sometimes true of your child. It the item is not true of your child, circle the $\underline{0}$. Please answer all items as well as you can, even if some do not seem to apply to your child.

0 = Not True (as far as you know)

1 = Somewhat or Sometimes True

2 = Very True or Often True

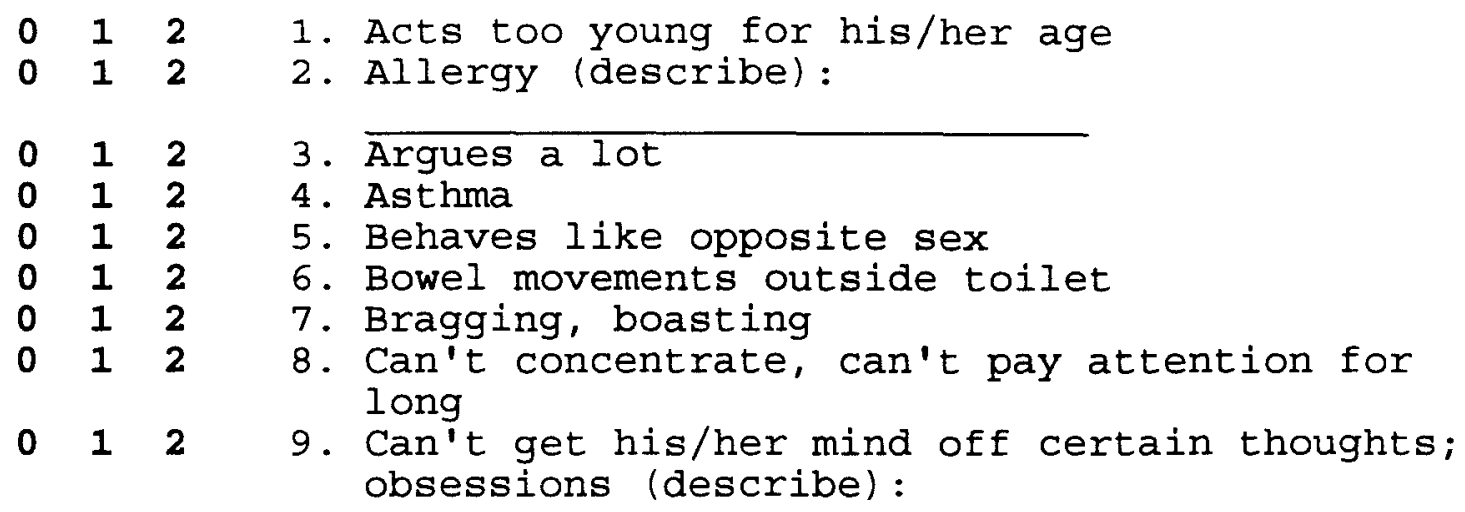

10. Can't sit still, restless, or hyperactive

11. Clings to adults or too dependent

12. Complains of loneliness

13. Confused or seems to be in a fog

14. Cries a lot

15. Cruel to animals

16. Cruelty, bulling, or meanness to others

17. Day-dreams or gets lost in his/her thoughts

18. Deliberately harms self or attempts suicide

19. Demands a lot of attention

20. Destroys his/her own things

21. Destroys things belonging to his/her family

22. Disobedient at home

23. Disobedient at school

24. Doesn't eat well

25. Doesn't get along with other children

26. Doesn't seem to feel guilty after misbehaving

27. Easily jealous

28. Eats or drinks things that are not food (describe) :

012 29. Fears certain animals, situations, or places, other than school (describe): 


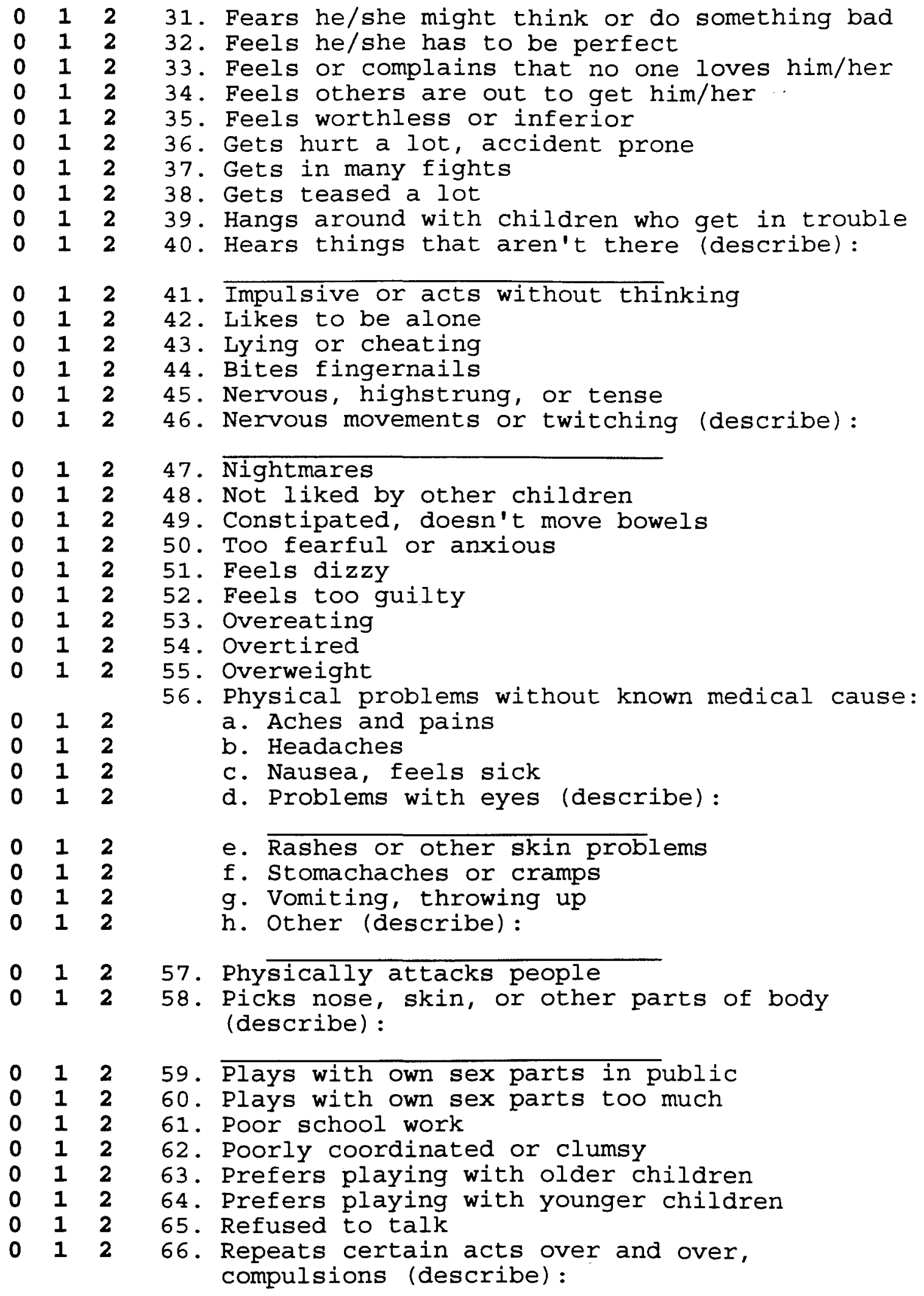




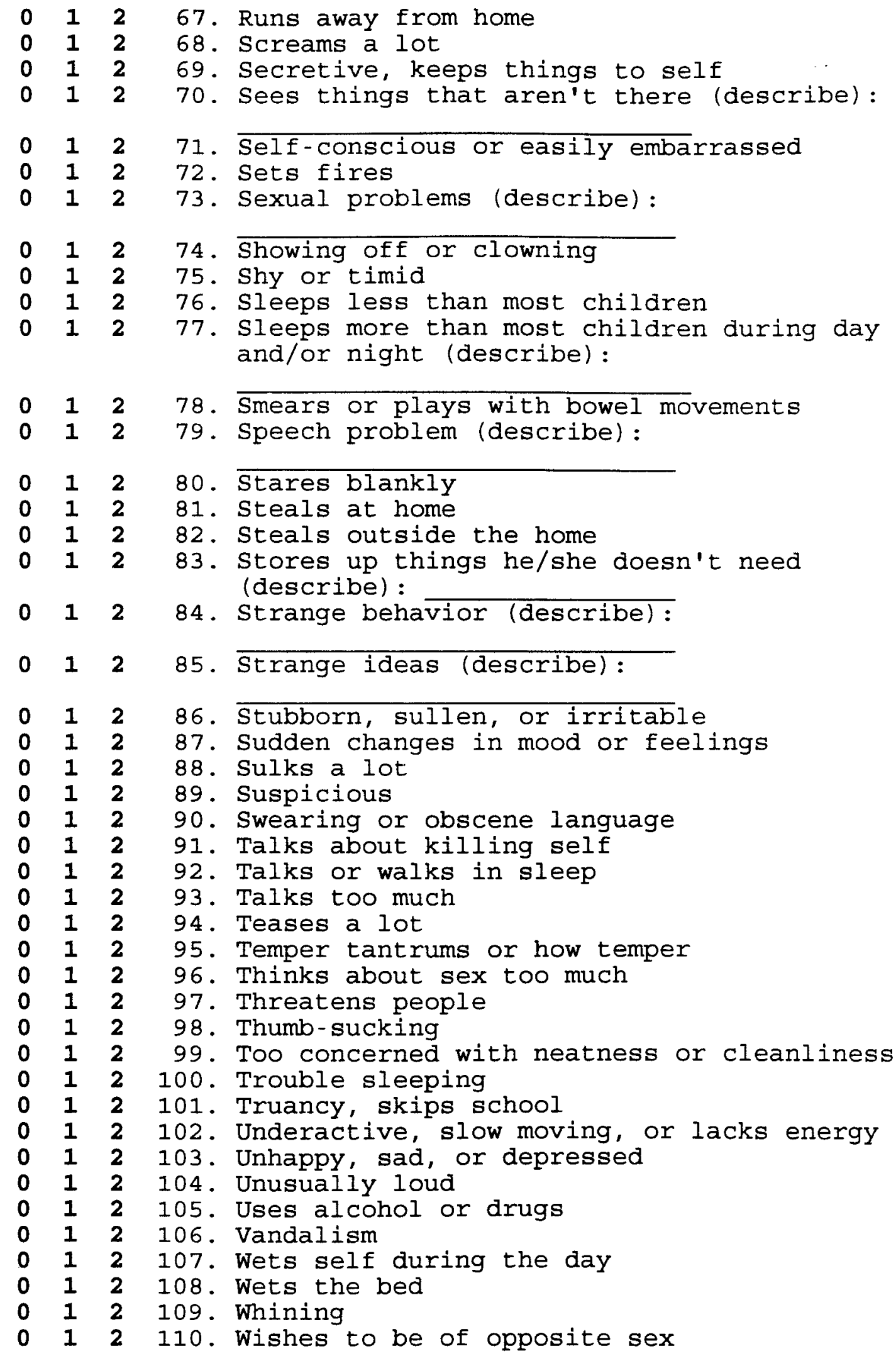


012 111. Withdrawn, doesn't get involved with others

012112 . Worrying

113. Please write in any problems your child has that were not 1 isted above:

$\begin{array}{lll}0 & 1 & 2 \\ 0 & 1 & 2 \\ 0 & 1 & 2\end{array}$ 
Please indicate what you feel to be your child's actual competence on each question, in your opinion. First decide what kind of child he or she is like, the one described on the top statement OR the bottom statement, and then indicate whether this is just sort of true or really true for your child. Thus, for each item, check one of four spaces.

1. My child is really good at his/her school work really true sort of true

$\mathrm{OR}$

My child can't do the school work assigned really true sort of true

2. My child finds it hard to make friends really true sort of true

OR

For my child it's pretty easy really true sort of true

3. My child does really well at all kinds of sports _ really true _ sort of true

OR

My child isn't very good when it comes to sports really true sort of true

4. My child is good-looking

really true sort of true

OR

My child is not very good-looking really true sort of true 
5. My child is usually well-behaved

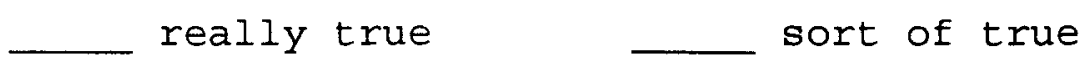

OR

My child is often not well-behaved really true sort of true

6. My child often forgets what he/she is learning really true sort of true

OR

My child can remember things easily really true sort of true

7. My child has a lot of friends really true sort of true

OR

My child doesn't have many friends really true sort of true

8. My child is better than others his/her age at sports really true sort of true

OR

My child can't play as well really true sort of true

9. My child has a nice physical appearance really true sort of true

OR 
My child doesn't have such a nice physical appearance really true sort of true

10. My child usually acts appropriately

$$
\text { really true }
$$

sort of true

OR

My child would be better if he/she acted differently

really true sort of true

11. My child has trouble figuring out the answers in school really true sort of true

OR

My child almost always can figure out the answers really true sort of true

12. My child is popular with others his/her age - really true sort of true

OR

My child is not very popular really true sort of true

13. My child doesn't do well at new outdoor games really true sort of true

OR

My child is good at new games right away really true sort of true

14. My child isn't very attractive really true sort of true 
OR

My child is pretty attractive

_really true sort of true

15. My child often gets in trouble because of things he/she does

$$
\text { really true _ sort of true }
$$

OR

My child usually doesn't do things that get him/her in trouble really true sort of true 
APPENDIX D

CHILDREN'S BELIEFS AND COPING SUBSCALES 
Children's Beliefs About Parental Conflict Scale Listing of Items for Each Subscale

\section{Peer Concerns}

1. It would upset me if other kids asked a lot of questions about my parents

7. I like talking to my friends as much now as I used to $(\mathrm{R}=$ reverse scored $)$

13. I like playing with my friends as much now as I used to (R)

19. I'd rather be alone than play with other kids

25. My friends and I do many things together (R)

31. My friends understand how I feel about my parents (R)

\section{Paternal Blame}

2. It was usually my father's fault when my parents had a fight

8. My father is usually a nice person (R)

14. When my family was unhappy it was usually because of something my father said

20. My father caused most of the trouble in my family

26. There are a lot of things about my father I like (R)

32. My father is more good than bad (R) 


\section{Fear of Abandonment}

3. I sometimes worry that both my parents will want to live without me

9. It's possible that both my parents will never want to see me again

15. I sometimes worry that I'll be left ali alone

21. I feel that my parents still love me (R)

27. I sometimes think that one day I may have to go live with a friend or relative

33. I feel my parents still like me (R)

\section{Maternal Blame}

4. When my family was unhappy it was usually because of my mother

10. My mother is usually a nice person (R)

16. Often I have a bad time when I'm with my mother

22. My mother caused most of the trouble in my family

28. My mother is more good than bad (R)

34. There are a lot of things about my mother I like (R)

\section{Hope of Resolution}

5. My parents will always fight

11. If I behave better I might be able to stop my parents from fighting

17. My family will probably stop fighting (R)

23. My parents will probably see that they have made mistakes and will stop fighting (R)

29. I sometimes think that my parents will one day stop fighting ( $R$ ) 
35. I sometimes think that once my parents realize how much I want them to, they'll stop fighting

\section{Self-Blame}

6. My parents often argue with each other after I misbehave

12. My parents would probably be happier if I were never born

18. My parents probably argue more when I'm with them than when I'm gone

24. My parents are happier when I'm with them than when I'm not (R)

30. I can make my parents unhappy with each other by what I say or do

36. My parents would probably not be fighting if it weren't for me 
Children's Coping Strategies Scale

Listing of Items for Each Subscale

\section{Ventilation}

1. I cry

9. I release, or let out, my feelings

17. I just let my feelings out

25. I yell and scream

Distraction

2. I do something that $I$ enjoy $(R=$ reverse scored $)$

10. I exercise or play a sport (R)

18. I go somewhere in order to relax (R)

26. I take a nap or go to sleep (R)

\section{Aggression}

3. I get into fights or argue with people

11. I take out my frustration on someone or something else

19. I throw things or break things

27. I hurt somebody who didn't have anything to do with the problem 
Self-destruction

4. I smoke cigarettes

12. I think about hurting myself

20. I take drugs or drink alcohol

28. I do something dangerous or risky

\section{Social Support}

5. I talk to others about how I'm feeling (R)

13. I succeed at telling others how I feel (R)

21. I find a close friend or family member to talk to about my problem (R)

29. I show people I'm close to how I'm feeling (R)

\section{Change Situation}

6. I try to change something about the situation to make it better ( $R$ )

14. I try to convince somebody to act differently (R)

22. I act to correct the problem in somebody or something else (R)

30. I solve the problem by getting someone else to change (R)

\section{Avoidance}

7. I avoid the problem

15. I keep my feelings and thoughts to myself

23. I act as though nothing has happened

31. I go off by myself 


\section{Change Self}

8. I change myself to make things better (R)

16. I change my actions to be a better person (R)

24. I change something about myself to sclve the problem (R)

32. I try to act differently myself in order to solve the problem (R) 


\section{REFERENCES}

Achenback, T., \& Edelbrock, C. (1983). Manual for the Child Behavior Checklist and Revised Child Behavior Checklist. Burlington: University of Vermont.

Achenback, T., \& Edelbrock, C. (1987). Manual for the Youth Self-Report and Profile. Burlington: University of Vermont.

Bishop, S. M., \& Ingersoll, G. M. (1989). Effects of marital conflict and family structure on the selfconcepts of pre- and early adolescents. Journal of Youth and Adolescence, 18, 25-38.

Cohen, J., \& Cohen, P. (1983). Applied multiple regression/correlation analysis for the behavioral sciences. Hillsdale, N.J.: Erlbaum.

Compas, B. E. (1987). Coping with stress during childhood and adolescence. Psychological Bulletin, 101, 393-403.

Compas, B. E., Malcarne, V. L., \& Fondacaro, K. M. (1988). Coping with stressful events in older children and young adolescents. Journal of Consulting and Clinical Psychology, 56, 405-411.

Cummings, E. M., Vogel, D., Cummings, J. S., \& ElSheikh, M. (1989). Children's responses to different forms of expression of anger between adults. Child Development, 60, 1392-1404.

Cummings, J. S., Pellegrini, D. S., Notarius, C. I., \& Cummings, E. M. (1989). Children's responses to angry adult behavior as a function of marital distress and history of interparental hostility. Child Development, 60, 1035-1043.

Dubow, E. F., Schmidt, D., McBride, J., Edwards, S. , \& Merk, F. Lynne. (1993). Teaching children to cope with stressful experiences: Initial implementation and evaluation of a primary prevention program. Journal of Clinical Child Psychology, 22, 428-440. 
Emery, R. E. (1982). Interparental conflict and the children of discord and divorce. Psychological Bulletin, 92, 310-330.

Emery, R. E. (1988). Marriage, divorce, and children's adjustment. Newbury Park: Sage.

Emery, R. E., \& O'Leary, K. D. (1982). Children's perceptions of marital discord and behavior problems of boys and girls. Journal of Abnormal Child Psychology, 10, $11-24$.

Fauber, R., Forehand, R., Thomas, A. M., Wierson, M. (1990), A mediational model of the impact of marital conflict on adolescent adjustment in intact and divorced families: The role of disrupted parenting. Child Development, 61, 1112-1123.

Fuhrman, T., \& Holmbeck, G. N. (1993). A contextual analysis of emotional autonomy and adjustment in adolescence. Manuscript submitted for publication.

Galambos, N, \& Dixon, R. (1984). Adolescent abuse and the development of personal sense of control. Child Abuse and Neglect, the International Journal, $\underline{8}, 285$ 294.

Garmezy, N., Masten, A., Nordstrom, L., \& Ferrarese, M. (1979). The nature of competence in normal and deviant children. In M. W. Kent \& J. E. Rolf (Eds.), Primary prevention of psychopathology. Vol. 3: Social competence in children. Hanover, $\mathrm{NH}$ : University Press of New England.

Gottman, J. M., \& Katz, L. F. (1989). Effects of marital discord on young children's peer interaction and health. Developmental Psychology, 25, 373-381.

Grych, J. H., \& Fincham, F. D. (1990). Marital conflict and children's adjustment: A cognitive-contextual framework. Psychological Bulletin, 108, 267-290.

Harter, S. (1982). The perceived competence scale for children. Child Development, 53, 87-97.

Harter, S. (1985). Manual for the Self-Perception Profile for Children. Denver: University of Denver.

Harter, S., \& Pike, R. (1984). The pictorial scale of perceived competence and social acceptance for young children. Child Development, 55, 1969-1982. 
Hughes, H. (1988). Psychological and behavioral correlates of family violence in child witnesses and victims. American Journal of Orthopsychiatry, $\underline{58}, 77-90$.

Johnson, P. L., \& O'Leary, K. D. (1987). Parental behavior patterns and conduct disorders in girls. Journal of Abnormal Child Psychology, 15, 573-581.

Johnston, J. R., Gonzalez, R., \& Campbell, L. E. (1987). Ongoing post-divorce conflict and child disturbance. Journal of Abnormal Child Psychology, 15, 497-509.

Jose, P. E. (1991). Children's coping strategies scale. Unpublished manuscript, Loyola University Chicago, Chicago, IL.

Jose, P. E., D'Anna, C., \& Cafasso, L. (1992, June). Coping strategies and social support moderate the effects of stress upon outcome measures for children. Paper presented at the 1992 convention of the American Psychological Society, San Diego, CA.

Jose, P. E., Cafasso, L. L., \& D'Anna, C. A. (in press). Ethnic group differences in children's coping strategies. Sociological studies of Children.

Jouriles, E. N., Barling, J., \& O'Leary, K. D. (1987). Predicting child behavior problems in maritally violent families. Journal of Abnormal Child Psychology, 15, 165-173.

Jouriles, E. N., Murphy, C. M. \& O'Leary, K. D. (1989). Interspousal aggression, marital discord, and child problems. Journal of Consulting and Clinical

Psychology, 57, 453-455.

Jouriles, E. N., Pfiffner, L. J., \& O'Leary, S. G. (1988). Marital conflict, parenting, and toddler conduct problems. Journal of Abnormal Child Psychology, 16, $197-206$.

Kazdin, A. E. (1981). Assessment techniques for childhood depression. Journal of the American Academy of Child Psychiatry, 20, 358-375.

Kazdin, A. E., French, N., H., Unis, A. S., EsveldtDawson, K., \& Sherick, R. B. (1983). Hopelessness, depression, and suicidal intent among psychiatrically disturbed inpatient children. Journal of Consulting and Clinical Psychology, 51, 504-510. 
Kovacs, M. (1981). Rating scales to assess depression in school-aged children. Acta Paedopsychiatrica, 46, 305 315 .

Kurdek, L. A., \& Berg, B. (1987). Children's beliefs about parental divorce scale: Psychometric characteristics and concurrent validity. Journal of Consulting and Clinical Psychology. 55, 712-718.

Lazarus, R. S., \& Folkman, S. (1984). Stress, appraisal, and coping. New York: Springer.

Long, B. H. (1986). Parental discord vs family structure: Effects of divorce on the self-esteem of daughters. Journal of Youth and Adolescence, 15, 19-27.

Long, B. H. (1987). Perceptions of parental discord and parental separations in the effects on daughters' attitudes toward marriage and courtship progress. The Journal of Social Psychology, 127, 573-582.

Long, N., Forehand, R., Fauber, R., \& Brody, G. H. (1987) . Self-perceived and independently observed competence of young adolescents as a function of parental marital conflict and recent divorce. Journal of Abnormal Child Psychology, 15, 15-27.

Long, N., Slater, E., Forehand, R., \& Fauber, R. (1988). Continued high or reduced interparental conflict following divorce: Relation to young adolescent adjustment. Journal of Consulting and Clinical Psychology, 56, 467-469.

Parker, J.G., \& Asher, S. R. (1987). Peer acceptance and later interpersonal adjustment: Are low-accepted children "at risk"? Psychological Bulletin, 102, 357 389 .

Porter, B., \& O'Leary, K. D. (1980). Marital discord and childhood behavior problems. Journal of Abnormal Child Psychology, 8, 287-295.

Prescott, S., \& Letko, C. (1977). Battered women: A social psychological perspective. In M. Roy (Ed.), Battered women: A psychosociological study of violence (pp. 72-96). New York: Van Nostrand Reinhold.

Quay, H. B., \& Peterson, D. R. (1979). Interim manual for the revised behavior problem checklist. Unpublished manuscript, University of Miami. 
Rosenberg, M. S. (1987). Children of battered women: The effects of witnessing violence on their social problemsolving abilities. Behavior Therapist, 4 , 85-89.

Roy, M. (1977). A current survey of 150 cases. In M. Roy (Ed.), Battered women: A psychosociological study of violence (pp. 25-44). New York: Van Nostrand Reinhold.

Rutter, M. (1979). Protective factors in children's responses to stress and disadvantage. In M. W. Kent \& J. E. Rolf (Eds.), Primary prevention of psychopathology. Vol. 3: Social competence in children. Hanover, $\mathrm{NH}$ : University Press of New England.

Rutter, M. (1983). Stress, coping, and development: Some issues and some questions. In N. Garmezy, \& M. Rutter (eds.), stress, coping, and development in children (pp. 1-41). New York: McGraw Hil1.

Shaw, D. S., \& Emery, R. E. (1987). Parental conflict and other correlates of the adjustment of school-age children whose parents have separated. Journal of Abnormal Child Psychology, 15, 269-281.

Spivak, G., \& Shure, M. B. (1982). Interpersonal problem solving and clinical theory. In B. Lahey \& A. E. Kazdin (Eds.), Advances in child clinical psychology (Vol. 5, pp. 323-372). New York: Plenum Press.

Spivak, G., \& Shure, M. B. (1985). The ICPS and beyond: Centripedal and centrifugal forces. American Journal of Community Psychology, 13, 226-243.

Straus, M. A. (1990). Manual for the Conflict Tactics Scales (CTS). Durham: University of New Hampshire.

Straus, M. A. (1979). Measuring intrafamily conflict and violence: The conflict tactics (CT) scales. Journal of Marriage and the Family, 41, 75-88.

Straus, M. A., \& Gelles, R. J. (1986). Societal change and change in family violence from 1975 to 1985 as revealed by two national surveys. Journal of Marriage and the Family, 48, 465-479.

Straus, M. A., Gelles, R. J., \& Steinmetz, S. K. (1980). Behind closed doors: Violence in the American family. New York: Doubleday. 
Varma, M. (1977). Battered women; battered children. In M. Roy (Ed.), Battered women: A psychosociological study of violence (pp. 263-276). New York: Van Nostrand Reinhold.

Wierson, M., Forehand, R., \& McCombs, A. (1988). The relationship of early adolescent functioning to parentreported and adolescent-perceived interparental conflict. Journal of Abnormal Child Psychology, 16, $707-718$.

Wolfe, D. A., Zak, L., Wilson, S., \& Jaffe, P. (1986). Child witnesses to violence between parents: Critical issues in behavioral and social adjustment. Journal of Abnormal Child Psychology, 14, 95-104. 
VITA

The author, Mary Jo Rogers, is the daughter of Betty (Peterson) Rogers and the late Ernest G. Rogers. She was born on March 9, 1963 in Ladysmith, Wisconsin.

Dr. Rogers received her Bachelor of Arts degree in psycrology in at the University of Wisconsin-Eau Claire in May, 1986. She went on to earn her Master of Arts degree in developmental psychology at Northern Illinois University before entering Loyola University's doctoral program in clinical psychology in August, 1989. During her training at Loyola, she specialized in the clinical treatment of children and adolescents and completed a pediatric clinical internship at La Rabida Children's Hospital in Chicago. Dr. Rogers' research interests have included the study of peer aggression, the effects of interparental aggression on children's adjustment, and post-traumatic stress disorders in abused children.

While finishing her dissertation research, Dr. Rogers began working at Mercy Hospital and Medical Center, where she is currently employed as a psychologist in the child and adolescent outpatient treatment program. 


\section{APPROVAL SHEET}

The dissertation submitted by Mary Jo Rogers has been read and approved by the following committee:

Dr. Grayson Holmbeck, Director

Associate Professor, Psychology

Loyola University Chicago

Dr. Maryse Richards

Associate Professor, Psychology

Loyola University Chicago

Dr. Paul Jose

Associate Professor, Psychology

Loyola University Chicago

Dr. Ana Estrada

Assistant Professor, Psychology

Loyola University Chicago

The final copies have been examined by the director of the dissertation and the signature which appears below verifies the fact that any necessary changes have been incorporated and that the dissertation is now given final approval by the Committee with reference to content and form.

The dissertation is therefore accepted in partial

fulfillment of the requirements for the degree of Doctor of Philosophy.

$2 / 16 / 24$

Date

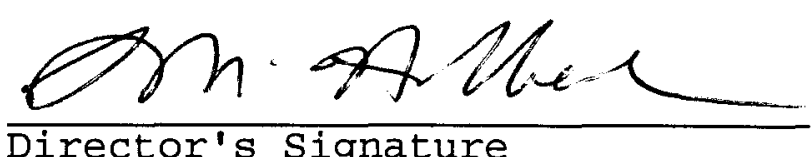

